Do People Want to Be More Moral?

\author{
Jessie Sun $^{1} \&$ Geoffrey P. Goodwin ${ }^{2}$ \\ ${ }^{1}$ University of California, Davis \\ ${ }^{2}$ University of Pennsylvania
}

\begin{abstract}
Author Note
Correspondence concerning this article should be addressed to Jessie Sun, Department of Psychology, University of California, Davis, 200 East Quad, Davis, CA, 95616. E-mail: jesun@ucdavis.edu
\end{abstract}

Postprint, 14 January 2020 (in press, Psychological Science)

This postprint may differ slightly from the final, copy-edited version of record. 


\begin{abstract}
Most people want to change some aspects of their personality, but does this phenomenon extend to moral character, and to close others? Targets $(N=800)$ and well-acquainted informants $(N=$ 958) rated targets' personality traits and reported how much they wanted the target to change each trait. Targets and informants reported a lower desire to change more morally-relevant traits (e.g., honesty, compassion, fairness), compared to less morally-relevant traits (e.g., anxiety, sociability, productiveness) — even after controlling for current trait levels. Moreover, although targets and informants generally wanted targets to improve more on traits that targets had less desirable levels of, targets' moral change goals were less calibrated to their current trait levels. Finally, informants wanted targets to change in similar ways, but to a lesser extent, than targets themselves did. These findings suggest that moral considerations take a backseat when it comes to self-improvement.
\end{abstract}

Keywords: volitional personality change, moral character, self-improvement, moral motivations, self-other agreement 


\section{Do People Want to Be More Moral?}

Most people want to change some aspects of their personality—across adulthood, over $78 \%$ of people express desires to be more extraverted, emotionally stable, conscientious, agreeable, or open to experience (Hudson \& Fraley, 2016b). To date, personality change goals have primarily been examined through the lens of the Big Five framework and the goals that people have for themselves (Baranski, Morse, \& Dunlop, 2017; Hudson \& Fraley, 2015; Hudson \& Roberts, 2014). Here, we examine whether the common desire for personality change extends to moral character, and to close others. In other words, do people want to be more moral, and do people who know us well want us to change in similar ways?

Personality traits describe relatively stable, enduring patterns of thoughts, feelings, and behaviors that make people different from one another (DeYoung, 2015). Moral character traits are personality traits that capture individual differences in the tendency to follow relevant moral standards-essentially, the extent to which someone is a "good" or "bad" person (Fleeson, Furr, Jayawickreme, Meindl, \& Helzer, 2014). Traits differ in the degree to which they are seen as being relevant to moral character (which can vary across cultures and individuals; Meindl \& Graham, 2014). For example, at least in Western contexts, extraversion is not considered to be particularly morally relevant (a "non-moral trait", for short-hand), whereas honesty is considered to be highly morally relevant (a "moral trait"; Meindl \& Graham, 2014). Thus, being generally introverted does not make someone a "bad person," whereas being generally dishonest might.

People place great value on morality in themselves and in others; indeed, some research suggests that feeling moral might be a basic psychological need (Prentice et al., 2018). Moral character traits are also among the most powerful determinants of the overall impressions we form of others (Goodwin, 2015; Goodwin, Piazza, \& Rozin, 2014; Hartley et al., 2016). Thus, if people recognize that their moral character influences how much other people like and respect 
them, then they might want to become more moral to not only reach their own moral standards, but to also attain the reputational benefits of being viewed as a moral person.

However, there are equally-compelling reasons to believe that people might be less motivated to change their moral traits (compared to non-moral traits). First, because people appear to inaccurately inflate their positive moral qualities to a greater extent compared to their non-moral qualities (Tappin \& McKay, 2017), they might see no need to further enhance their moral traits. Second, people might typically be more inclined to make changes that will assuage their dissatisfaction with aspects of their lives (Baumeister, 1994; Hudson \& Fraley, 2016a). For example, a person who is dissatisfied with their friendships might strive to become more extraverted to overcome these social difficulties (Hudson \& Roberts, 2014). In contrast, insofar as morality involves overcoming selfish impulses for the benefit of others (Baumeister \& Exline, 1999), the perceived costs of becoming more moral might outweigh its reputational benefits, dissuading people from striving for moral self-improvement.

Further complicating the picture is the fact that moral traits are seen as especially central to personal identity (for a review, see Strohminger, Knobe, \& Newman, 2017). Whereas some research suggests that people are less willing to (hypothetically) take pharmaceuticals to enhance traits that are more fundamental to identity (e.g., empathy, kindness; Riis, Simmons, \& Goodwin, 2008), other studies suggest that hypothetical improvements to moral traits might be seen as bringing people closer to their "true selves" (Bench, Schlegel, Davis, \& Vess, 2015; Christy, Kim, Vess, Schlegel, \& Hicks, 2017).

Little empirical evidence directly compares moral and non-moral change goals. In one study in which participants selected five characteristics that they most wanted to improve, the probability of wanting a moral trait to improve was $21 \%$ (vs. $47 \%$ for non-moral traits; Molouki \& Bartels, 2017). However, because this study was not designed to compare moral and non- 
moral personality change goals, it did not comprehensively sample moral and non-moral traits. Therefore, our primary aim is to comprehensively examine the extent to which people want to change more or less morally-relevant traits.

Our second goal was to document the ways in which other people want us to change our personality traits ("interpersonal change goals"). Because people who know us well have a unique perspective on our personalities (Vazire \& Carlson, 2011), close others could shape our personality change goals—and ultimately, our personalities— by pointing out areas for improvement that may or may not have occurred to us (Bollich, Johannet, \& Vazire, 2011). Consistent with this idea, when targets and informants agreed that the target was low on agreeableness and extraversion, this predicted stronger self-reported desires to improve these traits, compared to when targets and informants disagreed on targets' current levels (Quintus, Egloff, \& Wrzus, 2017). However, no study to our knowledge has asked informants about how they would like targets to change. Doing so would shed light on whether the people who know us well want us to change in ways that are similar to how we want ourselves to change. Evidence of self-other agreement on personality change goals would show that close others can corroborate our own assessments of which traits are most in need of improvement, whereas self-other disagreement might suggest that close others either have unique insight into our shortcomings, or want us to improve in ways that would benefit them.

Our final goal was to explore individual differences in the desire for moral selfimprovement. People who have less desirable levels of a given Big Five trait generally want to improve more on that trait (Baranski et al., 2017; Hudson \& Fraley, 2015; Hudson \& Roberts, 2014), but these correlations have been more consistent for extraversion, conscientiousness, and emotional stability than for agreeableness and openness. Here, we examine whether less desirable trait levels are associated with a greater desire to improve moral traits, or whether, alternatively, 
the most moral people are the ones who most want to improve their moral traits (i.e., that virtue begets virtue in the moral domain).

\section{Method}

We recruited two samples of participants so that we could freely explore the data in Sample 1, before preregistering and directly replicating these analyses in Sample 2 (see Supplemental Material for details). This preregistration, along with all materials and the data and analysis scripts needed to reproduce the current analyses are available at https://osf.io/cbxjh/. We determined our sample sizes (300/500 targets) based on time and budget constraints (and however many informants would respond); the resulting sample sizes exceed recommendations for obtaining stable estimates of the average published effect in personality and social psychology ( $N>250$; Schönbrodt \& Perugini, 2013). We report all data exclusions and all measures (measures not included in the current paper are reported in our OSF repository).

\section{Participants and Procedure}

We recruited two samples of target participants ("targets") from the undergraduate psychology research pools at the University of Pennsylvania (Sample 1) and the University of California, Davis (Sample 2). Apart from minor differences described below, we used the same data collection procedures for the two samples. Targets completed an online questionnaire (implemented using Qualtrics software) in which they nominated up to four informants who knew them well, then self-reported their personality traits and change goals (described below). Within the set of four informants, targets were asked to nominate at least two people who were not current romantic partners or family members. We invited informants to participate in the study by emailing them a unique link to an online questionnaire. Informants rated their target's personality traits and reported the personality changes they wanted to see in their target. We sent informants who had not yet completed the survey three (Sample 1) to six (Sample 2) email 
reminders, spaced approximately one week apart. In both samples, we used all available data for analyses involving only target self-reports (even if the target had no informant reports).

Targets participated in exchange for course credit. Informants who completed the survey were entered into a prize draw for a 1 in 10 chance of winning a $\$ 20$ Amazon.com gift card. In Sample 2, informants could also ask to be entered into the prize draw even if they did not participate (in compliance with California law). Data collection procedures were approved by the Institutional Review Board at the University of Pennsylvania (Sample 1; IRB ID: 831767) and the University of California, Davis (Sample 2; IRB ID: 1328211-2).

Sample 1. In Sample 1, 300 targets (224 female, 74 male, 2 other or not disclosed) between the ages of 18 and 29 years $\left(M_{\text {age }}=19.57, S D_{\text {age }}=1.29\right)$ completed the study and met our preregistered inclusion criteria (we excluded four participants who were under the age of 18). Targets identified as White/Caucasian $(n=143)$, Asian $(n=85)$, Hispanic/Latino $(n=24)$, Black/African American $(n=20)$, Pacific Islander $(n=1)$, Other/Multiple $(n=25)$, or did not disclose their ethnicity $(n=2)$. Targets successfully nominated 1,023 informants, of which 417 informants ( 288 female, 124 male, 5 other or not disclosed) between the ages of 18 and 98 years $\left(M_{\text {age }}=28.54, S D_{\text {age }}=15.22\right)$ completed the study (response rate $\left.=41 \%\right)$. Most targets $(n=$ 221) had at least one informant; of these, 129 targets had two or more informants. Most informants reported being friends of the target $(n=234)$, followed by parents $(n=97)$, current romantic partners $(n=37)$, siblings $(n=32)$, other family members $(n=8)$, other $(n=5)$, exromantic partners $(n=3)$, and co-workers $(n=1)$. On average, informants reported having known their targets for 9.39 years $(\mathrm{SD}=8.17)$. Following our preregistered stopping rules, we ended data collection for targets when 300 targets (who met our inclusion criteria) completed the study, 
and ended data collection for informants one week after the third email reminder had been sent to the last informants who were nominated.

Sample 2. Because informant response rates were lower in Sample 2, we deviated from our preregistered sampling plan by 1) sending three more email reminders to informants nominated by the first 300 targets and 2) recruiting 200 more targets (prior to analyzing the Sample 2 data). Thus, Sample 2 comprised 500 targets (404 female, 93 male, 3 other or not disclosed) between the ages of 18 and 47 years $\left(M_{\text {age }}=19.85, S D_{\text {age }}=2.55\right)$ who completed the study and met our preregistered inclusion criteria (none were excluded). Targets identified as White/Caucasian $(n=102)$, Asian $(n=236)$, Hispanic/Latino $(n=89)$, Black/African American ( $n=3)$, Pacific Islander $(n=3)$, Other/Multiple $(n=64)$, or did not disclose their ethnicity $(n=$ 3). Targets successfully nominated 1,464 informants, of which 541 informants (396 female, 135 male, 10 other or not disclosed) between the ages of 18 and 81 years $\left(M_{\text {age }}=25.63, S D_{\text {age }}=\right.$ 12.56) completed the study (response rate $=37 \%)$. Most targets $(n=288)$ had at least one informant; of these, 166 targets had two or more informants. Most informants reported being friends of the target $(n=334)$, followed by parents $(n=80)$, current romantic partners $(n=30)$, siblings $(n=57)$, other family members $(n=20)$, other $(n=8)$, ex-romantic partners $(n=3)$, and co-workers $(n=1)$. On average, informants reported having known their targets for 8.95 years $(\mathrm{SD}=7.85)$. We ended data collection one week after we sent the third email reminder to the informants who were nominated by the last 200 targets.

\section{Measures}

Targets and informants rated targets' current standing on 21 personality traits, and reported the extent to which they wanted the target to change each of these traits, using the following measures. 


\section{Personality traits.}

Big Five facets. The Big Five Inventory-2 (BFI-2; Soto \& John, 2017) measures fifteen facets (4 items each) of the Big Five personality domains: extraversion (sociability, assertiveness, energy level), agreeableness (compassion, respectfulness, trust), conscientiousness (organization, productiveness, responsibility), negative emotionality (anxiety, depression, emotional volatility), and open-mindedness (intellectual curiosity, aesthetic sensitivity, creative imagination). We also assessed an additional facet of Negative Emotionality (Anger), using two items from the Big Five Aspects Scale (DeYoung, Quilty, \& Peterson, 2007; "Gets angry easily" and "Is not easily annoyed" [r]). Targets rated the extent to which they agreed with 62 statements (e.g., "I am someone who is outgoing, sociable"), on a 5-point scale ( 1 = disagree strongly, $5=$ agree strongly). Informants rated the extent to which they agreed with the same statements about the target (e.g., "[target's name] is someone who is outgoing, sociable"). We dropped one item from the Aesthetic Sensitivity measure ("Values art and beauty") for reasons described below.

Moral characteristics questionnaire. The BFI-2 contains some morally relevant content, especially for the Agreeableness (e.g., "Is helpful and unselfish with others") and Conscientiousness (e.g., "Is reliable, can always be counted on") domains. However, other aspects of moral character are not well-captured by the BFI-2. Thus, we used the Moral Characteristics Questionnaire (MCQ; Prentice, Furr, \& Hawkins, in prep) to measure general morality (e.g., "I am a person of strong moral character"; 4 items), as well as the specific domains of honesty (e.g., "I consistently tell the truth”), fairness (e.g., "I treat people fairly”), loyalty (e.g., "I shift my loyalties easily" [r]), and purity ("I would say that I'm a wholesome person, relatively 'pure""; 2 items per domain). Targets and informants rated the extent to which they agreed with such statements about the target, on a 5-point scale $(1=$ strongly disagree, $5=$ strongly agree $)$. 
The original measures included two additional items for each domain (i.e., six items for general morality and four items for each of the other domains). However, whereas all but one of the BFI-2 items describe current tendencies, two items from each of the MCQ scales captured values and moral strivings (e.g., "I don't believe that honesty is that important", "I want to be honest even when it's hard"). As described in the Sample 2 preregistration, to avoid a confound when examining the correlation between traits and change goals (which, by definition, capture strivings), we dropped the MCQ items that captured values and strivings (and the "Values art and beauty" BFI-2 item), and only included the items that described current tendencies (e.g., "I tend to act morally") and overall self-perceptions (e.g., "I am an honest person").

\section{Personality change goals.}

Change goals scale. We measured change goals by modifying two items for each of the 21 personality traits (16 Big Five facets and 5 MCQ domains) described above. Following Hudson and Roberts (2014), we reworded the instructions, items, and response scales in terms of how much targets and informants wanted the target to change each personality trait (see codebook in the OSF repository for full item wordings). For example, "I am someone who is helpful and unselfish with others" was reworded to "I want to be helpful and unselfish with others" (self-report) or "I want [target's name] to be helpful and unselfish with others" (informant-report), with response options indicating the magnitude and direction of the desired changes $(-2=$ much less than I currently am, $-1=$ less than I currently am, $0=I$ do not want to change in this trait,$+1=$ more than I currently am, $+2=$ much more than I currently am; we adjusted the pronouns and grammar as needed for different items and for the informant reports).

We computed the mean of the two change goal items for each trait, separately for targets and informants. We also extracted an index of the overall desire for change by taking the average of the absolute scores across the 42 change goal items, separately for targets and informants 
(resulting in a continuous measure that has a possible range of 0 to 2 , where $0=$ no change desired on any of the 42 items, and 2 = "much more" or "much less" on all 42 items).

Change goal priorities. To get a better sense of which personality changes people would most prioritize, we showed targets and informants all of the desired changes they had selected from the full set of change goals (i.e., excluding the items for which they selected the response, "I do not want [target's name] to change on this trait"), and asked them to select the top three most desired changes ("Which three changes would you most like to see in yourself/[target's name]?"). On average, targets selected priorities out of a list of $M_{\text {Sample } 1}=26.44(S D=8.44)$ and $M_{\text {Samplez }}$ $=27.63(S D=9.32)$ desired changes, and informants selected priorities out of a list of $M_{\text {Sample } 1}$ $=12.40(S D=7.95)$ and $M_{\text {Samplez }}=12.86(S D=9)$ desired changes. See Supplemental Material for a description of the order in which this list was presented.

From the top three priorities, we computed 42 binary variables that represented whether or not a target or informant (respectively) had prioritized a goal to improve each of the 21 traits as one of their top three priorities. Each of the 21 traits we measured has an unambiguous "positive pole." For instance, previous research shows that most people want to increase on extraversion, conscientiousness, agreeableness, and openness, and to decrease on neuroticism - and fewer than $3 \%$ want to change in the opposite direction (Hudson \& Roberts, 2014). This indicates that most people think that low neuroticism and high levels on the other Big Five traits are desirable, and that changes towards these "positive poles" are improvements. Similarly, our moral valence norms (described below) showed that people generally consider general morality, honesty, fairness, loyalty, and purity to be morally positive. Thus, we operationalized "improvements" as change goals in the desirable direction (i.e., decreases on facets of negative emotionality, and increases on all other traits), which were coded as 1 . Not prioritizing a goal was coded as 0 , as 
were goals to change in the undesirable direction (as very few participants prioritized goals to change in the undesirable direction; see Figure 1).

Out of these top three priorities, we also asked targets and informants to select and provide an open-ended justification for their top change goal (which we use in supplemental analyses; see Supplemental Material).

Moral relevance. To examine whether change goals and other effects varied depending on the trait's moral relevance, we obtained norming data for the 42 items included in our change goals scale. We recruited two separate samples of trait raters from the same subject pools as the targets (while preventing target participants from signing up for the trait norming study). Trait raters were randomly assigned to one of two versions of the norming task (for a description of additional exploratory dimensions, see https://osf.io/cbxjh/). Only the first version of the task involved rating moral relevance. Thus, the trait raters included in this study comprised 114 Penn undergraduates ( 81 female, 32 male, 1 not disclosed, $M_{\text {age }}=19.53, S D_{\text {age }}=1.20$ ) and $203 \mathrm{UC}$ Davis undergraduates (165 female, 36 male, 2 not disclosed, $M_{\text {age }}=20.30, S D_{\text {age }}=3.32$ ).

Trait raters rated the moral valence of the 42 items in our change goals scale. Specifically, after reading a brief explanation of moral traits, participants were asked, "How morally good or morally bad is it to be high on each of the following traits?" (e.g., "Having a forgiving nature"; $3=$ Very morally bad, $-2=$ Moderately morally bad, $-1=$ Slightly morally bad, $0=$ Neither morally good nor morally bad, $+1=$ Slightly morally good, $+2=$ Moderately morally good,$+3=$ Very morally good). To index the moral relevance of each of the 21 traits, we computed the absolute value of the moral valence rating for each item, for each rater $(0=$ not morally relevant, $3=$ very morally relevant). Then, we averaged the two items for each trait, before computing the average moral relevance rating for each trait across all raters. These raters also rated the 
perceived changeability of each trait, which we use for supplemental analyses (described in the Supplemental Material). Descriptive statistics for the norming data are reported in Table S1.

We conducted analyses for each sample using the norms for the respective samples. The between-traits analyses (e.g., correlations between moral relevance and average absolute change goals) involved a relatively small set of 21 traits. This provided $80 \%$ power to detect correlations $>|.57|$, but limits our ability to detect smaller correlations (and therefore to draw conclusions about null effects for the between-traits analyses).

\section{Data Analyses}

Most analyses were conducted using R (R Core Team, 2018); some supplemental analyses used Mplus Version 8.3 (Muthén \& Muthén, 1998-2017). We used two complementary approaches: 1) the full change goals scale, and 2) the top three priorities. The first method captures the direction and amount of change that participants desired for each trait, whereas the second method summarizes the improvements that participants most prioritized. For each approach, we report descriptive statistics (means for the scale, frequencies for the priorities), and examine the associations between trait levels and change goals (correlations for the full scale in the main text, odds ratios for the priorities in the Supplemental Material).

For analyses involving informant reports, we computed an aggregate score across all informants for a given target, with two exceptions for our supplemental analyses: 1) we used all open-ended responses when examining reasons for the personality change that informants most prioritized, and 2) randomly selected one informant per target for the logistic regression analyses predicting informant-reported priorities from trait levels. For scale reliability estimates, we computed the omega $(\omega)$ coefficient for scales that had three or more items, and $\alpha$ for scales that had two items (using MBESS; Kelley, 2018). We repeated this procedure to compute scale reliabilities for the informant reports, after aggregating scores for each item across all informants 
for a given target. For the informant-reported measures, we computed the ICC(1) from a randomeffects model for targets who had two or more informants (using lme4; Bates, Mächler, Bolker, \& Walker, 2015). This represents the proportion of variation in the informant reports due to variation between targets.

For most of the key analyses (described below), we estimated latent correlations using structural equation models (SEMs), implemented via lavaan (Rosseel, 2012), to ensure that any differences in effect sizes across traits were not due to differences in measurement reliability (as some traits were measured with two items, and others with four items). For these SEMs, when there were only two indicators, we constrained the factor loadings for the two indicators to be equal, and constrained residual variances to be non-negative. Average effect sizes and comparisons of effect sizes were computed after appropriate transformations (described in the Supplemental Material).

\section{Results}

Descriptive statistics and self-other agreement correlations for the key measures are shown in Table 1 (for personality traits) and Table 2 (for change goals). The full correlation matrices for personality traits (Tables S6-S7) and change goals (Tables S8-S9) are available in the OSF repository. 
Table 1

Descriptive Statistics for Personality Traits

\begin{tabular}{|c|c|c|c|c|c|c|c|c|c|c|c|c|c|c|c|c|}
\hline \multirow[b]{3}{*}{ Trait } & \multicolumn{8}{|c|}{ Sample 1} & \multicolumn{8}{|c|}{ Sample 2} \\
\hline & \multicolumn{3}{|c|}{ Self-Report } & \multicolumn{4}{|c|}{ Informant-Report } & \multirow[b]{2}{*}{$r$} & \multicolumn{3}{|c|}{ Self-Report } & \multicolumn{4}{|c|}{ Informant-Report } & \multirow[b]{2}{*}{ 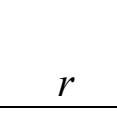 } \\
\hline & $M$ & $S D$ & $\omega$ & $M$ & $S D$ & $\omega$ & $I C C(1)$ & & $M$ & $S D$ & $\omega$ & $M$ & $S D$ & $\omega$ & $\operatorname{ICC}(1)$ & \\
\hline Sociability & 3.09 & 1.01 & .86 & 3.49 & 0.94 & .88 & .61 & $.74^{* * *}$ & 2.82 & 0.91 & .82 & 3.18 & 0.86 & .84 & .46 & $.63^{* * *}$ \\
\hline Assertiveness & 3.36 & 0.88 & .80 & 3.52 & 0.80 & .83 & .40 & $.55^{* * *}$ & 3.03 & 0.90 & .79 & 3.23 & 0.74 & .79 & .43 & $.51^{* * *}$ \\
\hline Energy Level & 3.70 & 0.78 & .72 & 4.04 & 0.69 & .73 & .43 & $.58^{* * *}$ & 3.43 & 0.79 & .66 & 3.79 & 0.72 & .75 & .35 & $.50^{* * *}$ \\
\hline Compassion & 3.93 & 0.72 & .57 & 4.10 & 0.70 & .72 & .16 & $.54^{* * *}$ & 3.78 & 0.69 & .47 & 4.00 & 0.61 & .61 & .12 & $.39^{* * *}$ \\
\hline Respectfulness & 3.98 & 0.67 & .62 & 4.26 & 0.62 & .75 & .28 & $.56^{* * *}$ & 3.97 & 0.65 & .59 & 4.22 & 0.64 & .76 & .26 & $.18^{*}$ \\
\hline Trust & 3.18 & 0.79 & .70 & 3.61 & 0.73 & .77 & .18 & $.48^{* * *}$ & 3.27 & 0.75 & .63 & 3.55 & 0.72 & .75 & .28 & $.44^{* * *}$ \\
\hline Organization & 3.80 & 0.90 & .82 & 3.79 & 0.95 & .90 & .51 & $.66^{* * *}$ & 3.83 & 0.85 & .81 & 3.83 & 0.90 & .89 & .40 & $.57^{* * *}$ \\
\hline Productiveness & 3.51 & 0.86 & .76 & 4.12 & 0.71 & .78 & .40 & $.59^{* * *}$ & 3.31 & 0.79 & .71 & 3.90 & 0.72 & .77 & .35 & $.56^{* * *}$ \\
\hline Responsibility & 3.56 & 0.69 & .59 & 4.00 & 0.67 & .74 & .25 & $.24^{* *}$ & 3.52 & 0.66 & .51 & 3.91 & 0.69 & .70 & .26 & $.33^{* * *}$ \\
\hline Anxiety & 3.66 & 0.86 & .79 & 3.35 & 0.87 & .84 & .31 & $.57^{* * *}$ & 3.64 & 0.84 & .74 & 3.29 & 0.75 & .78 & .26 & $.47^{* * *}$ \\
\hline Depression & 2.73 & 0.93 & .80 & 2.39 & 0.91 & .88 & .45 & $.62^{* * *}$ & 2.86 & 0.93 & .79 & 2.50 & 0.82 & .84 & .27 & $.40^{* * *}$ \\
\hline Emotional Volatility & 2.91 & 0.98 & .84 & 2.63 & 0.96 & .87 & .41 & $.55^{* * *}$ & 2.97 & 0.95 & .81 & 2.58 & 0.94 & .89 & .25 & $.43^{* * *}$ \\
\hline Anger & 2.94 & 1.02 & .62 & 2.60 & 0.94 & .73 & .31 & $.60^{* * *}$ & 2.94 & 1.01 & .56 & 2.68 & 0.91 & .71 & .28 & $.44^{* * *}$ \\
\hline Intellectual Curiosity & 4.08 & 0.66 & .68 & 4.13 & 0.65 & .76 & .25 & $.52^{* * *}$ & 3.79 & 0.73 & .72 & 3.90 & 0.66 & .75 & .33 & $.62^{* * *}$ \\
\hline Aesthetic Sensitivity & 3.61 & 1.00 & .73 & 3.69 & 0.88 & .82 & .44 & $.71^{* * *}$ & 3.44 & 0.94 & .62 & 3.57 & 0.81 & .70 & .39 & $.65^{* * *}$ \\
\hline Creative Imagination & 3.76 & 0.76 & .78 & 3.98 & 0.60 & .78 & .20 & $.44^{* * *}$ & 3.56 & 0.76 & .68 & 3.91 & 0.62 & .73 & .18 & $.20^{* *}$ \\
\hline General Morality & 4.06 & 0.60 & .77 & 4.47 & 0.46 & .73 & .05 & .15 & 3.99 & 0.57 & .69 & 4.35 & 0.47 & .70 & .12 & .10 \\
\hline Honesty & 3.94 & 0.69 & .75 & 4.37 & 0.58 & .76 & .05 & $.29^{* * *}$ & 3.89 & 0.74 & .77 & 4.31 & 0.59 & .74 & .13 & .13 \\
\hline Fairness & 4.16 & 0.54 & .67 & 4.47 & 0.50 & .75 & .17 & .12 & 4.18 & 0.59 & .68 & 4.44 & 0.50 & .74 & .13 & .10 \\
\hline Loyalty & 4.25 & 0.62 & .49 & 4.41 & 0.55 & .68 & .06 & $.24^{*}$ & 4.15 & 0.67 & .48 & 4.27 & 0.60 & .60 & .11 & -.02 \\
\hline Purity & 2.87 & 0.81 & .40 & 3.85 & 0.84 & .70 & .19 & $.31^{*}$ & 2.96 & 0.75 & .16 & 3.84 & 0.74 & .64 & .14 & $.39^{*}$ \\
\hline
\end{tabular}

Note. $\omega=$ omega reliability estimate, $I C C(1)=$ proportion of variability in informant ratings due to variability between targets (computed across informant ratings for targets who had two or more informants), $r=$ latent self-other agreement correlation, estimated using structural equation models. ${ }^{*} p<.05,{ }^{* *} p<.01,{ }^{* * *} p<.001$ (uncorrected for multiple comparisons). 
Table 2

Descriptive Statistics for Change Goals Scale

\begin{tabular}{|c|c|c|c|c|c|c|c|c|c|c|c|c|c|c|c|c|}
\hline \multirow[b]{3}{*}{ Change Goal } & \multicolumn{8}{|c|}{ Sample 1} & \multicolumn{8}{|c|}{ Sample 2} \\
\hline & \multicolumn{3}{|c|}{ Self-Report } & \multicolumn{4}{|c|}{ Informant-Report } & \multirow[b]{2}{*}{$r$} & \multicolumn{3}{|c|}{ Self-Report } & \multicolumn{4}{|c|}{ Informant-Report } & \multirow[b]{2}{*}{$r$} \\
\hline & $M$ & $S D$ & $\alpha$ & $M$ & $S D$ & $\alpha$ & $\operatorname{ICC}(1)$ & & $M$ & $S D$ & $\alpha$ & $M$ & $S D$ & $\alpha$ & $\operatorname{ICC}(1)$ & \\
\hline Anxiety & -1.18 & 0.63 & .56 & -0.79 & 0.61 & .79 & .30 & $.59^{* * *}$ & -1.25 & 0.67 & .65 & -0.78 & 0.58 & .70 & .16 & $.46^{* * *}$ \\
\hline Depression & -1.12 & 0.61 & .53 & -0.77 & 0.59 & .60 & .29 & $.61^{* * *}$ & -1.19 & 0.67 & .58 & -0.83 & 0.59 & .62 & .22 & $.52^{* * *}$ \\
\hline Productiveness & 0.99 & 0.64 & .68 & 0.24 & 0.43 & .60 & .30 & $.30^{* *}$ & 1.12 & 0.67 & .5 & 0.35 & 0.45 & .59 & .09 & $.25^{* *}$ \\
\hline Creative Imagination & 1.04 & 0.57 & .78 & 0.30 & 0.41 & .82 & .02 & .13 & 1.07 & 0.63 & .75 & 0.32 & 0.39 & .74 & .10 & .12 \\
\hline Anger & -0.90 & 0.66 & .69 & -0.40 & 0.49 & .79 & .18 & $.33^{* * *}$ & -1.03 & 0.74 & .75 & -0.42 & 0.52 & .80 & .13 & $.31^{* * *}$ \\
\hline Emotional Volatility & -0.96 & 0.64 & .56 & -0.47 & 0.54 & .70 & .29 & $.59^{* * *}$ & -0.98 & 0.73 & .52 & -0.46 & 0.53 & .62 & .06 & $.46^{* * *}$ \\
\hline Sociability & 0.88 & 0.61 & .69 & 0.41 & 0.52 & .80 & .34 & $.37^{* * *}$ & 1.00 & 0.67 & .63 & 0.55 & 0.50 & .73 & .15 & $.23^{* *}$ \\
\hline Organization & 0.79 & 0.65 & .84 & 0.33 & 0.47 & .72 & .20 & $.39^{* * *}$ & 0.84 & 0.66 & .81 & 0.35 & 0.52 & .89 & .27 & $.33^{* * *}$ \\
\hline Energy Level & 0.74 & 0.55 & .66 & 0.30 & 0.43 & .77 & .25 & $.40^{* * *}$ & 0.84 & 0.64 & .67 & 0.38 & 0.45 & .73 & .18 & $.29^{* * *}$ \\
\hline Intellectual Curiosity & 0.69 & 0.60 & .59 & 0.30 & 0.41 & .68 & .08 & .10 & 0.77 & 0.62 & .46 & 0.33 & 0.42 & .57 & .11 & $.31^{* *}$ \\
\hline Assertiveness & 0.67 & 0.61 & .62 & 0.34 & 0.51 & .75 & .22 & $.41^{* * *}$ & 0.75 & 0.64 & .53 & 0.44 & 0.52 & .71 & .16 & $.18^{*}$ \\
\hline Responsibility & 0.62 & 0.60 & .79 & 0.21 & 0.38 & .86 & .13 & .08 & 0.76 & 0.64 & .64 & 0.23 & 0.38 & .75 & .13 & $.18^{*}$ \\
\hline Honesty & 0.60 & 0.58 & .68 & 0.17 & 0.36 & .78 & .01 & .07 & 0.69 & 0.65 & .75 & 0.21 & 0.37 & .79 & .13 & $.29^{* * *}$ \\
\hline Aesthetic Sensitivity & 0.65 & 0.53 & .59 & 0.27 & 0.40 & .84 & .01 & .13 & 0.67 & 0.63 & .69 & 0.32 & 0.42 & .81 & .16 & $.16^{*}$ \\
\hline Trust & 0.60 & 0.60 & .43 & 0.27 & 0.46 & .69 & .12 & $.43^{* * *}$ & 0.56 & 0.67 & .36 & 0.24 & 0.43 & .60 & .07 & $.22^{*}$ \\
\hline Respectfulness & 0.57 & 0.60 & .64 & 0.16 & 0.33 & .61 & .10 & $.22^{*}$ & 0.69 & 0.67 & .59 & 0.20 & 0.40 & .66 & .13 & $.30^{* * *}$ \\
\hline General Morality & 0.59 & 0.55 & .75 & 0.08 & 0.30 & .79 & .17 & .03 & 0.61 & 0.61 & .69 & 0.15 & 0.34 & .76 & .17 & $.20^{* *}$ \\
\hline Compassion & 0.53 & 0.60 & .62 & 0.22 & 0.40 & .67 & .15 & $.28^{* *}$ & 0.57 & 0.64 & .54 & 0.18 & 0.37 & .65 & .16 & $.27^{* *}$ \\
\hline Fairness & 0.52 & 0.55 & .78 & 0.12 & 0.26 & .71 & .07 & -.02 & 0.58 & 0.60 & .77 & 0.15 & 0.33 & .81 & .11 & $.26^{* * *}$ \\
\hline Loyalty & 0.40 & 0.54 & .66 & 0.12 & 0.27 & .84 & .01 & -.00 & 0.52 & 0.63 & .75 & 0.16 & 0.36 & .84 & .12 & $.16^{*}$ \\
\hline Purity & 0.26 & 0.50 & .24 & 0.01 & 0.25 & .21 & .08 & -.26 & 0.32 & 0.57 & .08 & 0.03 & 0.31 & .31 & .10 & .23 \\
\hline
\end{tabular}

Note. ICC $(1)$ = proportion of variability in informant ratings due to variability between targets (computed across informant ratings for targets who had two or more informants),$r=$ latent self-other agreement correlation, estimated using structural equation models. ${ }^{*} p<.05,{ }^{* *} p<.01$, ${ }^{* * *} p<.001$ (uncorrected for multiple comparisons). Traits are ordered from the highest to lowest mean absolute desired change (averaged across both samples). The means reported in this table were computed from the raw change goals, but we used mean absolute change goals for the correlations with moral relevance and perceived changeability (reported in-text). 


\section{Do People Want to Be More Moral?}

As shown in Table 2 and Figures 1 and 2, targets showed the strongest desires to decrease on all facets of negative emotionality (anxiety, depression, emotional volatility, anger), and to increase on creative imagination, productiveness, and sociability. In contrast, targets reported weaker desires to change traits that were more morally relevant (e.g., honesty, general morality, compassion, fairness). To further understand this pattern, for each trait, we converted each participant's change goal into an absolute value, then averaged those values across participants to compute the average amount of desired change for each trait. This procedure places equal weight on goals to change in either direction (e.g., goals to become more or less compassionate both contributed to higher average absolute change goals for this analysis). We then correlated the average absolute change goal for each trait with the traits' moral relevance scores (rated by a separate sample of participants). This showed that on average, targets showed a lower desire to change traits that were more morally relevant, $r(19)=-.69,95 \% \mathrm{CI}[-.86,-.37], p<.001$ (Sample 1) and $r(19)=-.62,95 \% \mathrm{CI}[-.83,-.26], p=.003$ (Sample 2).

Figure 2, which summarizes participants' top three most desired changes for the target, makes the targets' personality change priorities even clearer. For these analyses, change goals that reflected a "worsening" of the trait (which fewer than $2 \%$ of participants prioritized for each trait) were not included. By focusing on participants' desire to "improve" each trait, these analyses directly address the main question of whether people want to be more moral. We found that targets were less inclined to prioritize more morally-relevant improvements (Sample 1: $r(19)$ $=-.56,95 \%$ CI $[-.80,-.17], p=.009$; Sample 2: $r(19)=-.57,95 \%$ CI $[-.80,-.18], p=.007)$. Instead, they focused on reducing negative emotionality. For example, a large proportion of the targets reported that becoming less anxious (Sample 1: 47.67\%; Sample 2: 41.80\%) or less depressed (Sample 1: 44.33\%; Sample 2: 37.60\%) were among their top three personality change 
goals. These were followed by goals to become more sociable (Sample 1: 25.67\%; Sample 2:

$30.80 \%$ ), less emotionally volatile (Sample 1: 19\%; Sample 2: 21.40\%), and more productive

(Sample 1: 19\%; Sample 2: 21.20\%). Moral improvements were rarely prioritized; for example, only $\sim 9 \%$ and $\sim 3 \%$ of targets prioritized a goal to become more compassionate or more generally

moral, respectively.
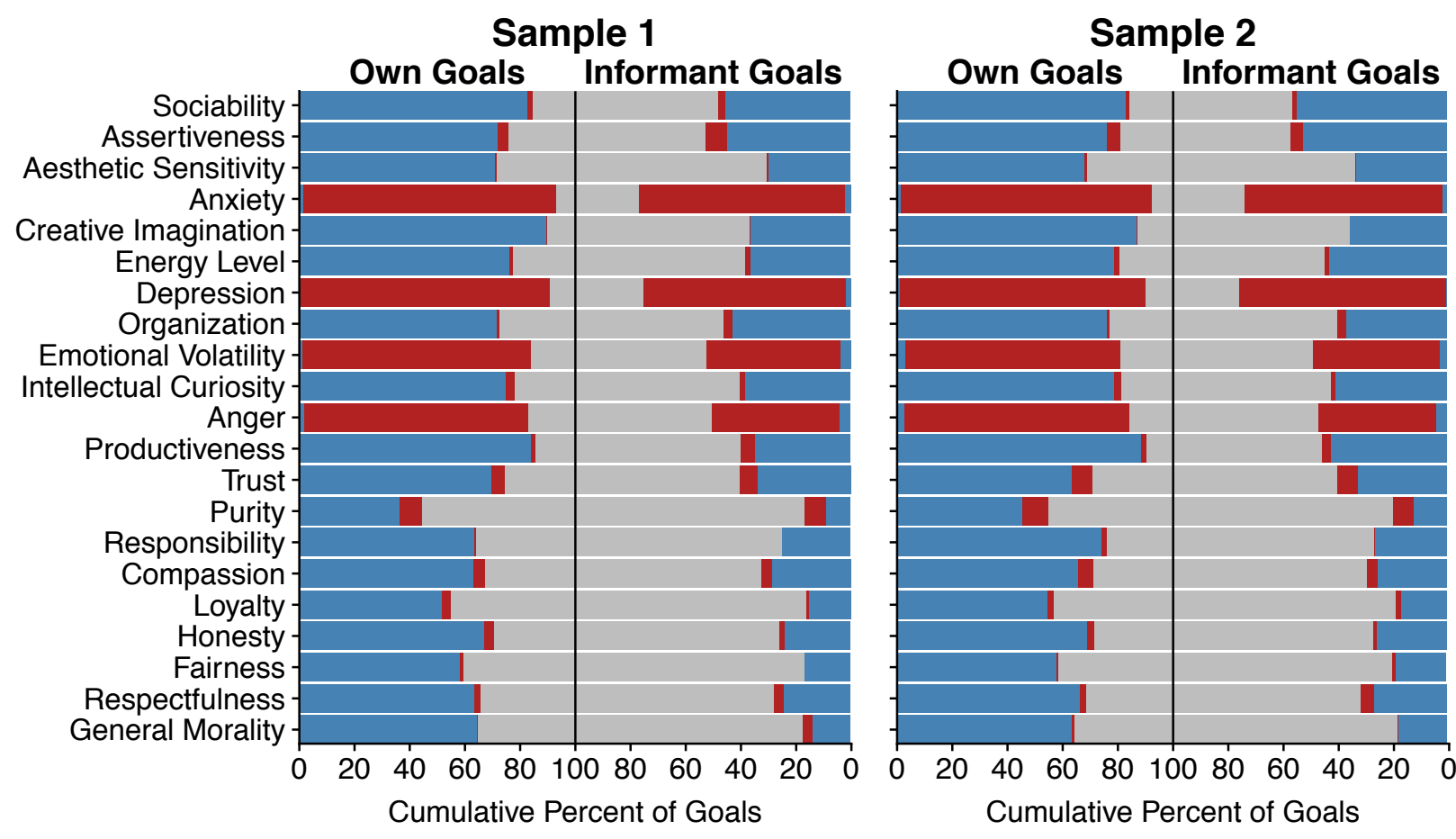

Want to Stay the Same

Want Lower Levels

Want Higher Levels

Figure 1. Categorical summary of change goals scale. Bars represent the percentage of targets or individual informants (i.e., not aggregated informants) who wanted the target to increase, decrease, or stay the same on each trait. To facilitate visual comparison, the traits are ordered from least to most morally relevant, based on the average of the moral relevance norms across the two samples (weighted equally). However, the analyses for each sample used the moral relevance norms for the respective sample. 

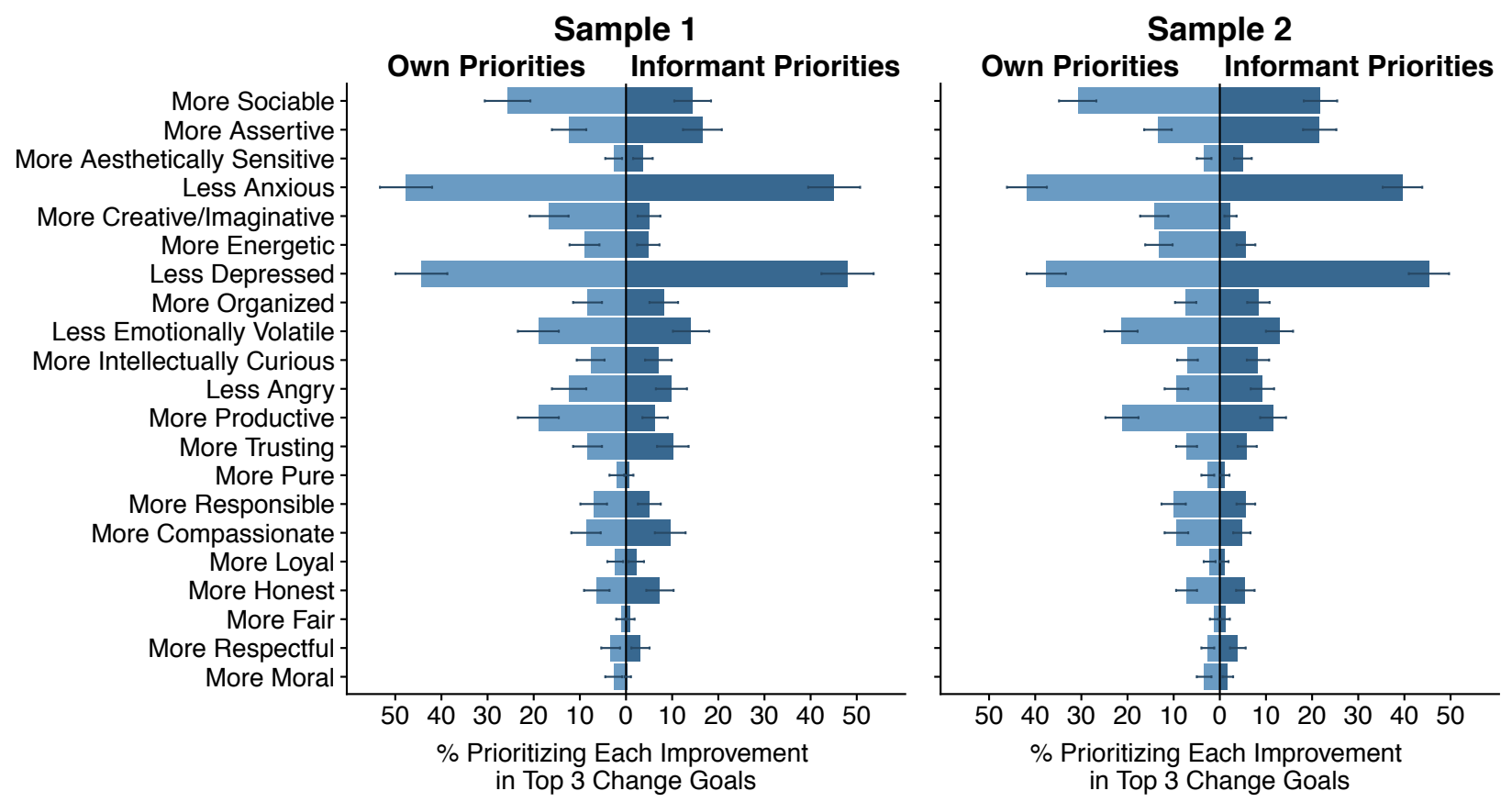

Figure 2. The percentage of targets or informants who prioritized each trait as one of their top 3 most desired changes. To facilitate visual comparison, the change goals are ordered from least to most morally relevant, based on the average of the moral relevance norms across the two samples (weighted equally). However, the analyses for each sample used the moral relevance norms for the respective sample. Error bars depict $95 \%$ confidence intervals.

\section{Do Close Others Want Us to Be More Moral?}

Next, we examined whether close others wanted their targets to change to a similar extent and in similar ways as the targets themselves. First, we compared targets' and informants' average absolute change goals across the 42 items (scores on this index ranged from 0 to 2 ). Paired-samples $t$-tests showed that on average, targets wanted to change themselves more (Sample 1: $M=0.79, S D=0.33$; Sample 2: $M=0.86, S D=0.38$ ) than their close others wanted them to change (Sample 1: $M=0.35, S D=0.22, g=1.55,95 \%$ CI $[1.33,1.77]$; Sample 2: $M=$ $0.38, S D=0.25, g=1.50,95 \%$ CI $[1.31,1.68])$. This pattern can be seen most clearly in Figure 1 - the gray bars (depicting the percentage of targets or informants who did not want the target to change a given trait) are much larger for the informants, across all traits. In addition, the average extent to which close others wanted the target to change was descriptively very similar for both 
friends (Sample 1: $M=0.33, S D=0.23$; Sample 2: $M=0.36, S D=0.27$ ) and parents (Sample 1: $M=0.34, S D=0.23$; Sample 2: $M=0.30, S D=0.23$ ).

Although informants typically wanted the targets to change less than the targets themselves did, they reported a similar pattern of change goals across traits, across targets, and within targets. Across traits, targets and informants showed a similar pattern of personality change priorities: the two sets of percentages (which included goals to change in the undesirable direction) correlated at $r(40)=.95,95 \%$ CI $[.90, .97], p<.001$ (Sample 1) and $r(40)=.93,95 \%$ CI $[.87, .96], p<.001$ (Sample 2). Mirroring the results for self-reported change goals, informants also reported lower desires to change more morally-relevant traits, $r(19)=-.68,95 \%$ CI $[-.86,-.35], p<.001$ (Sample 1) and $r(19)=-.71,95 \%$ CI $[-.87,-.40], p<.001$ (Sample 2), and were less likely to prioritize more morally-relevant improvements, $r(19)=-.46,95 \% \mathrm{CI}[-$ $.74,-.03], p=.037$ (Sample 1) and $r(19)=-.53,95 \%$ CI [-.78, -.13], $p=.013$ (Sample 2).

We used two additional methods to examine the similarity between self- and informantrated change goals. First, for each trait, we computed the latent correlation between self-reported change goals and informant-reported change goals (i.e., self-other agreement; see Table 2). These estimates were generally moderately positive (Sample 1: mean $r=.26$; Sample 2: mean $r=$ .28), suggesting that targets and informants agreed to some extent on how much targets should increase or decrease on each trait. For example, if a target reported that they wanted to become much less anxious, their informants also tended to report greater goals to reduce the target's anxiety (compared to a target who reported not wanting to reduce their anxiety).

Second, we computed profile correlations. Profile correlations describe the similarity between two sets of goals (i.e., across all 21 traits), as opposed to the between-person agreement for a given trait. They therefore allow us to examine the extent of similarity between a target's idiosyncratic profile of change goals and their informants' profile of change goals for them. 
However, profile correlations can be positive simply due to normativeness effects (e.g., because the average person wants to decrease on depression and increase on sociability; Furr, 2008). Because of such effects, it is theoretically possible that an "informant" who had never met a given target could report change goals that substantially overlap with that target's goals. Therefore, we compared the average overall profile correlation to a baseline based on many "pseudo-samples" in which we randomly paired up each target's profile of 21 change goals with the profile of 21 change goals reported by a different target's informant(s), and recomputed the profile correlations based on 1,000 such pseudo-samples (using multicon; Sherman \& Serfass, 2015). From this, we found that the mean overall $r$ for both samples was $.65(p<.001)$. After removing normativeness effects (i.e., agreement due to the average change goal profile), there was still a small amount of distinctive profile agreement (Sample 1: $r=.20, p<.001$; Sample 2: $r$ $=.12, p<.001)$. That is, targets and informants showed some agreement on the profile of changes that they wanted to see in the target, over and above mere normativeness effects.

\section{Who Wants to Be More Moral?}

Although people were generally less inclined to change more morally-relevant traits, some people showed a greater desire to change morally-relevant traits (relative to other people). Thus, we explored the correlates of these individual differences in moral change goals.

Associations between traits and change goals. First, we examined whether change goals were generally calibrated to the targets' current traits. Figure 3 (and Table S10 in the OSF repository) shows the latent correlations between current levels and change goals for each trait. Replicating the pattern observed in previous studies (e.g., Hudson \& Roberts, 2014), in general, targets who reported being lower on a given trait wanted to increase more on that trait (Sample 1: mean $r=-.52$; Sample 2: mean $r=-.35$ ). However, the negative association between traits and change goals was smaller for more morally-relevant traits, as shown by a strong positive 
association between moral relevance scores and (Fisher $r$-to- $z$ transformed) correlations between traits and change goals (Sample 1: $r(19)=.55,95 \%$ CI $[.16, .79], p=.010$; Sample 2: $r(19)=.49$, $95 \% \mathrm{CI}[.07, .76], p=.026)$. That is, knowing someone's current standing on a more morallyrelevant trait provides relatively little information about whether they want to increase or decrease on that trait.

We then examined the associations between informant-reported current traits and change goals. A paired-samples $t$-test showed that the negative association between traits and change goals was even stronger when both were informant-reported, compared to when both were selfreported (Sample 1: mean $r_{\text {informant }}=-.79, t(20)=5.97, p<.001$; Sample 2: mean $r_{\text {informant }}=$ $-.69, t(20)=11.39, p<.001)$. In addition, there was no evidence that the association between informant-reported traits and change goals was weaker for more morally-relevant traits (Sample 1: $r(19)=.29,95 \%$ CI $[-.16, .64], p=.198 ;$ Sample $2: r(19)=.33,95 \%$ CI $[-.12, .67], p=.142$; but note that we had relatively low power to detect these effects). However, there was no significant interaction between moral relevance and whether traits and change goals were both self-reported (the reference category) or both informant-reported (Sample 1: $b=-0.17,95 \% \mathrm{CI}$ $[-0.34,0.01], p=.083$; Sample 2: $b=-0.05,95 \%$ CI $[-0.18,0.09], p=.507)$.

We conducted conceptually similar logistic regression analyses, predicting change goal priorities from current levels. This alternative approach (see Supplemental Material) showed that targets who had less desirable levels of a trait were more likely to prioritize improving that trait as one of their top three change goals, and that informants' change goals remained relatively calibrated to their perceptions of targets' deficits, even for morally-relevant traits. 


\section{Sample 1}

Self-Reported Traits and Change Goals Informant-Reported Traits and Change Goals

\section{Trait}

Sociability

Assertiveness

Aesthetic Sensitivity

Anxiety

Organization

Creative Imagination

Energy Level

Depression

Emotional Volatility

Intellectual Curiosity

Anger

Productiveness

Trust

Purity

Responsibility

Compassion

Loyalty

Honesty

Respectfulness

Fairness

General Morality

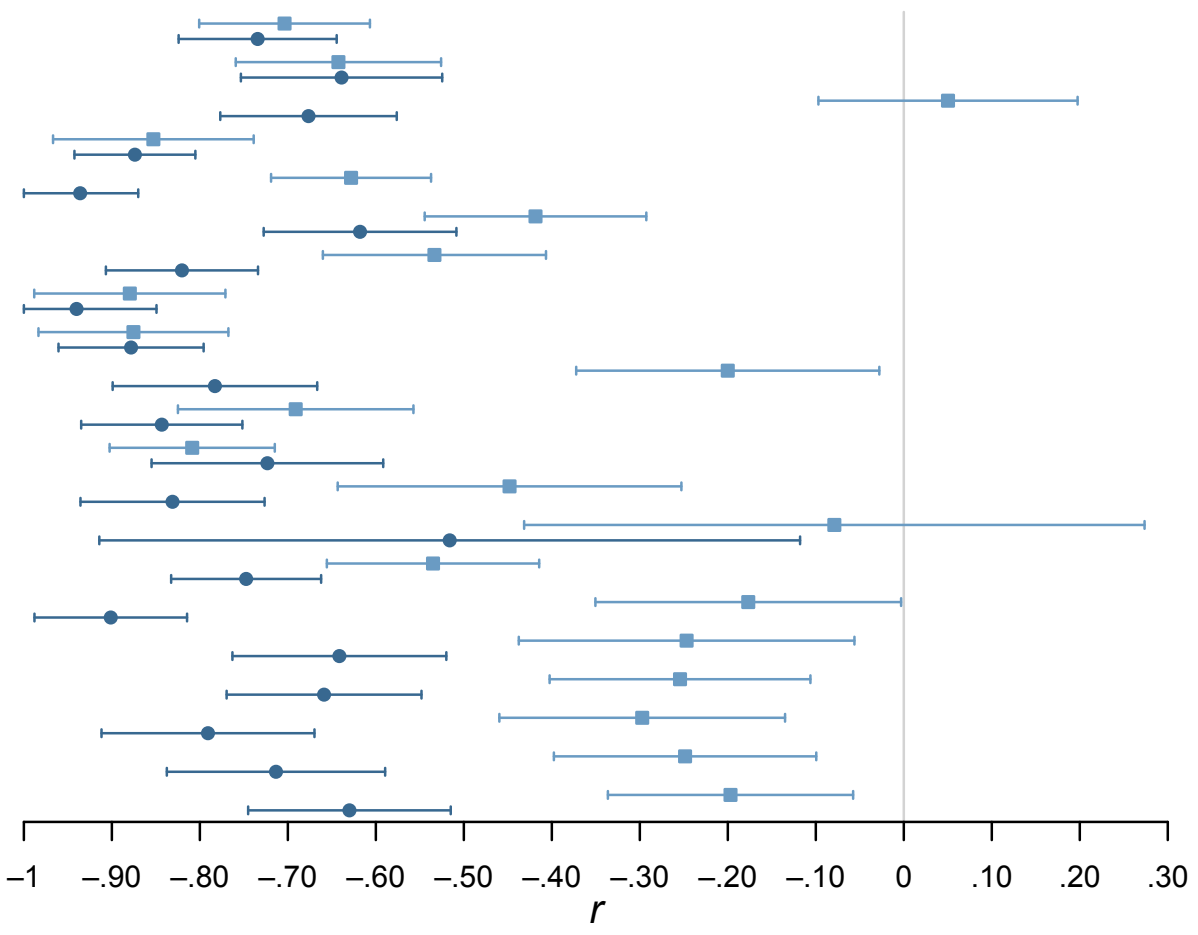

\section{Sample 2}

Self-Reported Traits and Change Goals Informant-Reported Traits and Change Goals

\section{Trait}

Sociability

Aesthetic Sensitivity

Assertiveness

Intellectual Curiosity

Anxiety

Depression

Creative Imagination

Emotional Volatility

Energy Level

Organization

Anger

Productiveness

Trust

Purity

Responsibility

Compassion

General Morality

Honesty

Loyalty

Fairness

Respectfulness

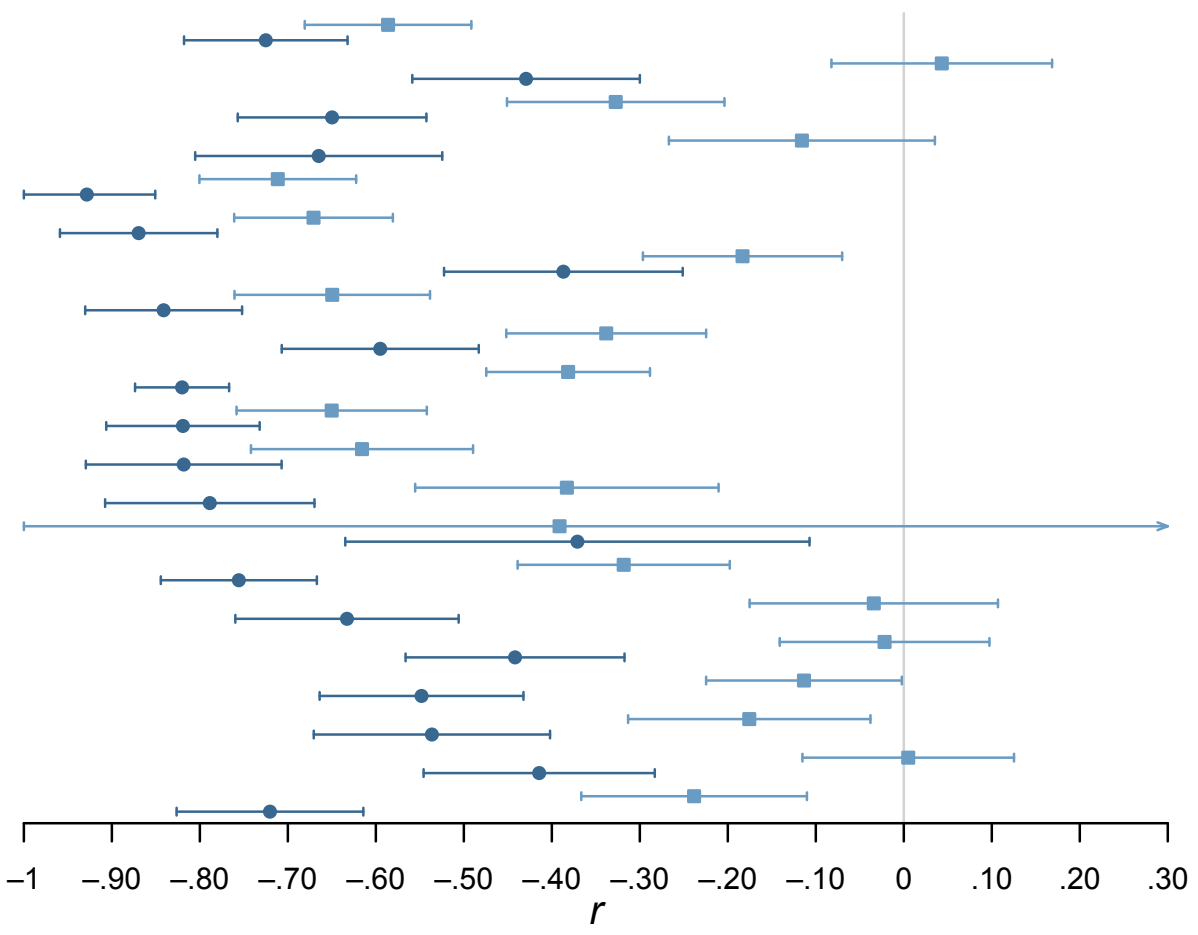

Figure 3. Associations between current traits and change goals. Error bars depict the $95 \%$ confidence intervals. The traits are ordered from least to most morally relevant, based on the moral relevance norms for each respective sample. 
Associations with additional individual differences. The above results showed that selfreported moral change goals were, at best, only weakly negatively correlated with self-reported levels on the respective traits. To find out whether moral change goals are related to other aspects of moral character and values, we used semi-partial correlations to examine the associations that each self-reported moral change goal had with a number of additional individual differences relating to moral character and values, controlling for self-reported levels on the trait in question. Two replicable and theoretically noteworthy findings were that more religious targets tended to report greater desires to increase on compassion and loyalty (controlling for self-reported compassion and loyalty, respectively), and that those who valued impartially maximizing the greater good (Kahane et al., 2018) reported greater desires to become fairer and more compassionate (controlling for self-reported fairness and compassion, respectively; see Supplemental Material and Tables S3-S4 for full details).

\section{Do High Trait Levels Explain Why People Don't Want to Be More Moral?}

Finally, because ratings tended to be quite high for most of the morally-relevant traits, we explored the possibility that people are less motivated to improve moral traits because they already see themselves or their close others as being relatively high on such traits (compared to less morally-relevant traits). To test this idea, we conducted supplemental within-person analyses using multi-level models. Across both samples, person-mean-centered trait levels and moral relevance independently predicted lowered change goals for both the continuous and prioritybased measures, and for both self- and informant-perspectives (these analyses were not preregistered; for details, see Supplemental Material and Table S2). In other words, people were less inclined to change the traits that they saw themselves (or their targets) as being relatively higher on (compared to the target's other traits) — but even after controlling for their perceptions of targets' current levels, they were still less inclined to change more morally-relevant traits. 


\section{Discussion}

We examined whether people want to be more moral, and whether close others also want our moral qualities to improve. Two findings stand out. First, people were less interested in changing moral traits (e.g., honesty, fairness, compassion), compared to non-moral traits (e.g., anxiety, sociability, productiveness), in themselves and in close others. Second, targets and informants showed similar patterns of change goals, but targets wanted to change themselves to a much greater extent than did their informants.

Why don't people particularly want to be more moral? Although self-ratings tended to be high for moral traits, ceiling effects cannot explain our main result, because our measure of change goals allowed participants to report how much they wanted to increase, decrease, or stay the same on each trait, independently of how they currently rated themselves. A more psychologically interesting possibility is that people see less room for improvement on moral traits. Because we did not measure where people think they stand relative to the extremes of each trait, our data cannot speak directly to this idea (i.e., people might not be claiming that they have the lowest or highest possible levels of each trait when they "strongly disagree" or "strongly agree" with each trait description; Blanton \& Jaccard, 2006). A related possibility is that people are less motivated to improve moral traits because they already see themselves as being quite high on such traits, and therefore morally "good enough"- even if they think they could be morally better (see Schwitzgebel, 2019). However, even after controlling for current levels, people were still less inclined to change more morally-relevant traits, suggesting that additional psychological factors might reduce people's desire to change morally-relevant traits.

One such possibility is that people are typically motivated to change in ways that will improve their own well-being (Hudson \& Fraley, 2016). Whereas becoming less anxious has obvious personal benefits, people might believe that becoming more moral would result in few 
personal benefits (or even costs). Supporting this idea, targets' and informants' justifications for their top change goal suggested that non-moral improvements would primarily benefit the target, whereas moral improvements would primarily benefit others (see Supplemental Material). Our findings are also consistent with the idea that people are reluctant to change moral traits because they are fundamental to their identity (e.g., Riis et al., 2008).

Considering how much people value morality in others (Goodwin, 2015; Goodwin et al., 2014; Hartley et al., 2016), it is perhaps more surprising that people don't want their close others to improve their moral qualities. Instead, like targets, informants prioritized wanting targets to become less anxious and depressed — and their open-ended justifications for these goals overwhelmingly reflected a concern for the targets' well-being (see Supplemental Material). Similar mechanisms might explain why people don't want themselves (described above) and others to become more moral. An additional possible explanation — specific to interpersonal change goals - is that people are less likely to become or stay close with social partners who have very different moral values in the first place (Haidt, Rosenberg, \& Hom, 2003; Skitka, 2010).

Finally, targets who had less desirable levels of a given trait wanted to improve more on that trait, but this was less true for more morally-relevant traits. For example, self-perceived deficiencies on compassion and general morality were not particularly indicative of how much targets wanted to improve these traits. Interestingly, however, informants' change goals were generally well-calibrated to their perceptions of targets' deficits-including moral deficits. This suggests that close others might have unique insight into not only our trait levels (Quintus et al., 2017; Vazire \& Carlson, 2011), but also which of our traits are most in need of improvement.

\section{Constraints on Generality}

Our goal in asking targets to self-nominate well-acquainted informants was to understand interpersonal change goals in the context of real-world relationships. Thus, we do not expect our 
findings regarding interpersonal change goals to generalize beyond people who already like and are close to the targets. We would likely see a greater desire to change targets in general - and perhaps a greater desire to change moral traits specifically—if we recruited informants who disliked the targets (Leising, Erbs, \& Fritz, 2010). Nor do our results speak to the moral change goals that people might have for abstract entities such as outgroups or people in general.

Does our main finding — that people are relatively unenthusiastic about moral selfimprovement—generalize beyond the unique developmental context of young adulthood? For example, given that concerns for nurturing and guiding the next generation tend to peak in midlife (McAdams, de St. Aubin, \& Logan, 1993), midlife adults might be more likely to prioritize moral improvements that serve these goals. We conducted another preregistered replication, which showed that relatively older adults (mean age $=45.4$ years) are also less inclined to improve more morally relevant traits (see Supplemental Material). Thus, we conclude that across the adult lifespan, people in Western cultures deprioritize moral self-improvements. Future research should investigate how other people want targets of different ages to change. For example, although parents of our young adult targets wanted them to change less than the targets themselves did, we speculate that parents might want to see greater moral development in younger children, even before children start thinking about changing their own personalities (but we have no idea what age range this might apply to).

\section{Conclusion}

People care a lot about morality, but does that mean that they want themselves and close others to be more moral? We found that North American college students might not value moral improvements as much as non-moral improvements in themselves, and that their close others typically feel the same way. This suggests that personality change goals might be primarily motivated by the desire to improve one's own life, rather than by more noble considerations. 
Still, on an uplifting note, close others generally accept us for who we are, but overwhelmingly want us to change in ways that have our best interests in mind.

\section{Author Contributions}

J. Sun conceptualized the study, collected and analyzed the data, and drafted the manuscript. G. Goodwin provided extensive feedback on the study design, analyses, and interpretations. Both authors revised the manuscript.

\section{Acknowledgements}

We are grateful to Ted Schwaba, Luke Smillie, and Joshua Wilt for comments on an earlier draft of this article, to colleagues at UC Davis and UPenn for insightful conversations, and to Rebecca Neufeld and Nicholas Hunt for assistance with data collection and coding.

\section{Open Practices}

Sample 1 was exploratory, and Sample 2 was a preregistered direct replication. The preregistration, all measures, and the data, $\mathrm{R}$ scripts, and Mplus input and output files required to reproduce the results reported in this paper are available at https://osf.io/cbxjh. 


\section{References}

Baranski, E. N., Morse, P. J., \& Dunlop, W. L. (2017). Lay conceptions of volitional personality change: From strategies pursued to stories told. Journal of Personality, 85(3), 285-299. https://doi.org/10.1111/jopy.12240

Bates, D., Mächler, M., Bolker, B., \& Walker, S. (2015). Fitting linear mixed-effects models using lme4. Journal of Statistical Software, 67(1), 1-48. https://doi.org/10.18637/jss.v067.i01

Baumeister, R. F. (1994). The crystallization of discontent in the process of major life change. In T. F. Heatherton \& J. L. Weinberger (Eds.), Can personality change? (pp. 281-297). Washington, DC: American Psychological Association. https://doi.org/10.1037/10143-012

Baumeister, R. F., \& Exline, J. J. (1999). Virtue, personality, and social relations: Self-control as the moral muscle. Journal of Personality, 67(6), 1165-1194. https://doi.org/10.1111/14676494.00086

Bench, S. W., Schlegel, R. J., Davis, W. E., \& Vess, M. (2015). Thinking about change in the self and others: The role of self-discovery metaphors and the true self. Social Cognition, 33(3), 169-185. https://doi.org/10.1521/soco.2015.33.3.2

Blanton, H., \& Jaccard, J. (2006). Arbitrary metrics in psychology. The American Psychologist, 61(1), 27-41. https://doi.org/10.1037/0003-066X.61.1.62

Bollich, K. L., Johannet, P. M., \& Vazire, S. (2011). In search of our true selves: Feedback as a path to self-knowledge. Frontiers in Psychology, 2, 1-6. https://doi.org/10.3389/fpsyg.2011.00312

Christy, A. G., Kim, J., Vess, M., Schlegel, R. J., \& Hicks, J. A. (2017). The reciprocal relationship between perceptions of moral goodness and knowledge of others' true selves. Social Psychological and Personality Science, 8(8), 910-917. 
https://doi.org/10.1177/1948550617693061

DeYoung, C. G. (2015). Cybernetic Big Five Theory. Journal of Research in Personality, 56,

33-58. https://doi.org/10.1016/j.jrp.2014.07.004

DeYoung, C. G., Quilty, L. C., \& Peterson, J. B. (2007). Between facets and domains: 10 aspects of the Big Five. Journal of Personality and Social Psychology, 93(5), 880-896. https://doi.org/10.1037/0022-3514.93.5.880

Fleeson, W., Furr, R. M., Jayawickreme, E., Meindl, P., \& Helzer, E. G. (2014). Character: The prospects for a personality-based perspective on morality. Social and Personality Psychology Compass, 8(4), 178-191. https://doi.org/10.1111/spc3.12094

Goodwin, G. P. (2015). Moral character in person perception. Current Directions in Psychological Science, 24(1), 38-44. https://doi.org/10.1177/0963721414550709

Goodwin, G. P., Piazza, J., \& Rozin, P. (2014). Moral character predominates in person perception and evaluation. Journal of Personality and Social Psychology, 106(1), 148-168. https://doi.org/10.1037/a0034726

Haidt, J., Rosenberg, E., \& Hom, H. (2003). Differentiating diversities: Moral diversity is not like other kinds. Journal of Applied Social Psychology, 33(1), 1-36. https://doi.org/10.1111/j.1559-1816.2003.tb02071.x

Hartley, A. G., Furr, R. M., Helzer, E. G., Jayawickreme, E., Velasquez, K. R., \& Fleeson, W. (2016). Morality's centrality to liking, respecting, and understanding others. Social Psychological and Personality Science, 7(7), 648-657. https://doi.org/10.1177/1948550616655359

Hudson, N. W., \& Fraley, R. C. (2015). Volitional personality trait change: Can people choose to change their personality traits? Journal of Personality and Social Psychology, 109(3), 490507. https://doi.org/10.1037/pspp0000021 
Hudson, N. W., \& Fraley, R. C. (2016a). Changing for the better? Longitudinal associations between volitional personality change and psychological well-being. Personality and Social Psychology Bulletin. https://doi.org/10.1177/0146167216637840

Hudson, N. W., \& Fraley, R. C. (2016b). Do people's desires to change their personality traits vary with age? An examination of trait change goals across adulthood. Social Psychological and Personality Science, 7(8), 847-856. https://doi.org/10.1177/1948550616657598

Hudson, N. W., \& Roberts, B. W. (2014). Goals to change personality traits: Concurrent links between personality traits, daily behavior, and goals to change oneself. Journal of Research in Personality, 53, 68-83. https://doi.org/10.1016/j.jrp.2014.08.008

Kahane, G., Everett, J. A. C., Earp, B. D., Caviola, L., Faber, N. S., Crockett, M. J., \& Savulescu, J. (2018). Beyond sacrificial harm: A two-dimensional model of utilitarian psychology. Psychological Review, 125(2), 131-164. https://doi.org/10.1037/rev0000093

Leising, D., Erbs, J., \& Fritz, U. (2010). The letter of recommendation effect in informant ratings of personality. Journal of Personality and Social Psychology, 98(4), 668-682. https://doi.org/10.1037/a0018771

McAdams, D. P., de St. Aubin, E., \& Logan, R. L. (1993). Generativity among young, midlife, and older adults. Psychology and Aging, 8(2), 221-230. https://doi.org/10.1037/08827974.8.2.221

Meindl, P., \& Graham, J. (2014). Know thy participant: The trouble with nomothetic assumptions in moral psychology. In H. Sarkissian \& J. C. Wright (Eds.), Advances in Experimental Moral Psychology (pp. 233-252). London: Bloomsbury. https://doi.org/10.5040/9781472594150.ch-012

Molouki, S., \& Bartels, D. M. (2017). Personal change and the continuity of the self. Cognitive Psychology, 93, 1-17. https://doi.org/10.1016/j.cogpsych.2016.11.006 
Muthén, L., \& Muthén, B. O. (1998-2017). Mplus user's guide (8th ed.). Los Angeles: Author.

Prentice, M., Furr, R. M., \& Hawkins, A. (in prep). Introducing the moral characteristics questionnaire. Manuscript in preparation.

Prentice, M., Jayawickreme, E., Hawkins, A., Hartley, A., Furr, R. M., \& Fleeson, W. (2018). Morality as a basic psychological need. Social Psychological and Personality Science. https://doi.org/10.1177/1948550618772011

Quintus, M., Egloff, B., \& Wrzus, C. (2017). Predictors of volitional personality change in younger and older adults: Response surface analyses signify the complementary perspectives of the self and knowledgeable others. Journal of Research in Personality, 70, 214-228. https://doi.org/10.1016/j.jrp.2017.08.001

R Core Team. (2018). R: A language and environment for statistical computing. R Foundation for Statistical Computing, Vienna, Austria.

Riis, J., Simmons, J. P., \& Goodwin, G. P. (2008). Preferences for enhancement pharmaceuticals: The reluctance to enhance fundamental traits. Journal of Consumer Research, 35(3), 495508. https://doi.org/10.1086/588746

Rosseel, Y. (2012). lavaan: An R package for structural equation modeling. Journal of Statistical Software, 48(2), 1-36. https://doi.org/10.18637/jss.v048.i02

Schönbrodt, F. D., \& Perugini, M. (2013). At what sample size do correlations stabilize? Journal of Research in Personality, 47(5), 609-612. https://doi.org/10.1016/j.jrp.2013.05.009

Schwitzgebel, E. (2019). Aiming for moral mediocrity. Res Philosophica, 96(3), 347-368.

Sherman, R. A., \& Serfass, D. G. (2015). The comprehensive approach to analyzing multivariate constructs. Journal of Research in Personality, 54, 40-50. https://doi.org/10.1016/j.jrp.2014.05.002

Skitka, L. J. (2010). The psychology of moral conviction. Social and Personality Psychology 
Compass, 4(4), 267-281. https://doi.org/10.1111/j.1751-9004.2010.00254.x

Soto, C. J., \& John, O. P. (2017). The next Big Five Inventory (BFI-2): Developing and assessing a hierarchical model with 15 facets to enhance bandwidth, fidelity, and predictive power. Journal of Personality and Social Psychology, 113(1), 117-143. https://doi.org/10.1037/pspp0000096

Strohminger, N., Knobe, J., \& Newman, G. (2017). The true self: A psychological concept distinct from the self. Perspectives on Psychological Science, 12(4), 551-560. https://doi.org/10.1177/1745691616689495

Tappin, B. M., \& McKay, R. T. (2017). The illusion of moral superiority. Social Psychological and Personality Science, 8(6), 623-631. https://doi.org/10.1177/1948550616673878

Vazire, S., \& Carlson, E. N. (2011). Others sometimes know us better than we know ourselves. Current Directions in Psychological Science, 20(2), 104-108.

https://doi.org/10.1177/0963721411402478 


\section{Additional Methodological Details}

\section{Preregistration Details}

Prior to collecting any data, we preregistered stopping rules for both samples and a preliminary analysis plan for Sample 1. Data collection for the two samples occurred around the same time, but we only conducted analyses for Sample 2 after preregistering the replication analysis code. Prior to uploading this preregistration, we only accessed the Sample 2 data for the purposes of extracting the informant contact information (to contact the informants that the targets nominated), and tracking how many informants had completed the study (which was handled by research assistants who were not involved in data analytic decisions).

\section{Successful Nominations}

A nomination was "unsuccessful" if the target nominated themselves, provided a name but no email address, provided an email address of a different person than the one they nominated (and we noticed), or nominated people who informed us that they did not know the target.

\section{Randomization Procedures for Change Goals Priorities}

The order of the list was randomized, but due to human error in programming the survey, it was presented in a fixed order for all targets, and different fixed orders for the three (male, female, and gender-neutral) versions of the informant survey (as the randomization had been conducted separately for these surveys). For Sample 1, rank-order Spearman correlations between the order in which a trait was presented and the probability that it was selected as one of the top three priorities did not support the idea that targets and informants were systematically selecting change goals that were closer to the top of the list $(\rho \mathrm{s}>-.22, p \mathrm{~s}>.156)$. For Sample 2 , this error also applied to the first 300 targets and their informants, but we subsequently corrected 
the issue such that the traits were presented in a randomized order for the last 200 targets and their informants. This error did not apply to Sample 3.

\section{Procedures for Effect Size Comparisons}

We computed average correlations by applying the Fisher $r$-to- $z$ transformation, taking the mean of the resulting $z$ statistics, then transforming the mean $z$ back to a $r$. We computed average ORs by computing the mean of the unstandardized $b$ coefficients, then exponentiating the mean $b$. When comparing the relative size of sets of correlations depending on whether they were based on self-reports, informant-reports, or across methods (as in Figure 3), we applied the Fisher $r$-to- $z$ transformation, before conducting parametric analyses on the resulting $z$ values. Similarly, when comparing the sizes of estimates from the logistic regression results or correlating these effects with other variables, we used the unstandardized $b$ coefficients. 


\section{Descriptive Statistics for Moral Relevance and Changeability Norms}

Table S1

Trait and Item Norms for Moral Relevance and Changeability

\begin{tabular}{|c|c|c|c|c|c|c|c|c|c|c|c|c|}
\hline & \multicolumn{6}{|c|}{ Sample 1} & \multicolumn{6}{|c|}{ Sample 2} \\
\hline & \multicolumn{3}{|c|}{ Moral Relevance } & \multicolumn{3}{|c|}{ Changeability } & \multicolumn{3}{|c|}{ Moral Relevance } & \multicolumn{3}{|c|}{ Changeability } \\
\hline & $M$ & $S D$ & $\alpha$ & $M$ & $S D$ & $\alpha$ & $M$ & $S D$ & $\alpha$ & $M$ & $S D$ & $\alpha$ \\
\hline General Morality & 2.67 & 0.56 & .63 & 4.60 & 1.32 & .69 & 2.22 & 0.86 & .68 & 4.67 & 1.23 & .49 \\
\hline Being a person of strong moral character & 2.65 & 0.69 & & 4.34 & 1.47 & & 2.25 & 0.98 & & 4.52 & 1.50 & \\
\hline Acting morally & 2.68 & 0.61 & & 4.85 & 1.54 & & 2.19 & 0.98 & & 4.83 & 1.52 & \\
\hline Respectfulness & 2.34 & 0.55 & .56 & 5.55 & 1.21 & .82 & 2.44 & 0.64 & .67 & 5.39 & 1.28 & .65 \\
\hline Being respectful, treating others with respect & 2.66 & 0.58 & & 5.58 & 1.28 & & 2.63 & 0.69 & & 5.40 & 1.47 & \\
\hline Being rude to others & 2.03 & 0.73 & & 5.53 & 1.35 & & 2.25 & 0.79 & & 5.38 & 1.51 & \\
\hline Fairness & 2.51 & 0.66 & .82 & 4.78 & 1.24 & .70 & 2.26 & 0.74 & .69 & 4.96 & 1.19 & .59 \\
\hline Treating everyone as fairly as possible & 2.56 & 0.67 & & 5.11 & 1.39 & & 2.32 & 0.82 & & 5.12 & 1.45 & \\
\hline Being a fair person & 2.46 & 0.75 & & 4.45 & 1.44 & & 2.19 & 0.87 & & 4.80 & 1.38 & \\
\hline Honesty & 2.33 & 0.72 & .73 & 4.78 & 1.42 & .87 & 2.23 & 0.75 & .71 & 4.92 & 1.32 & .78 \\
\hline Being an honest person & 2.34 & 0.81 & & 4.77 & 1.47 & & 2.25 & 0.87 & & 4.95 & 1.45 & \\
\hline Being honest even when it's hard & 2.32 & 0.81 & & 4.79 & 1.55 & & 2.22 & 0.83 & & 4.90 & 1.47 & \\
\hline Loyalty & 2.32 & 0.75 & .82 & 4.67 & 1.38 & .75 & 2.23 & 0.79 & .75 & 4.69 & 1.35 & .71 \\
\hline Being a loyal person & 2.35 & 0.79 & & 4.74 & 1.53 & & 2.32 & 0.85 & & 4.81 & 1.61 & \\
\hline Being loyal even when it's hard & 2.28 & 0.85 & & 4.60 & 1.55 & & 2.15 & 0.92 & & 4.57 & 1.45 & \\
\hline Compassion & 2.26 & 0.68 & .58 & 4.38 & 1.17 & .42 & 2.15 & 0.74 & .56 & 4.58 & 1.19 & .52 \\
\hline Being helpful and unselfish with others & 2.49 & 0.69 & & 4.94 & 1.46 & & 2.33 & 0.84 & & 4.95 & 1.51 & \\
\hline Being compassionate, having a soft heart & 2.03 & 0.92 & & 3.82 & 1.50 & & 1.98 & 0.92 & & 4.22 & 1.37 & \\
\hline Responsibility & 1.85 & 0.81 & .71 & 4.68 & 1.37 & .81 & 2.02 & 0.81 & .64 & 4.79 & 1.21 & .71 \\
\hline Being reliable, can always be counted on & 1.97 & 0.90 & & 4.66 & 1.47 & & 2.11 & 0.89 & & 4.73 & 1.43 & \\
\hline Being dependable, steady & 1.72 & 0.95 & & 4.71 & 1.52 & & 1.93 & 0.99 & & $\begin{array}{r}4.85 \\
\quad(t a\end{array}$ & $\begin{array}{c}1.32 \\
\text { le cont }\end{array}$ & ues) \\
\hline
\end{tabular}


Table S1 (continued)

\begin{tabular}{|c|c|c|c|c|c|c|c|c|c|c|c|c|}
\hline & \multicolumn{6}{|c|}{ Sample 1} & \multicolumn{6}{|c|}{ Sample 2} \\
\hline & \multicolumn{3}{|c|}{ Moral Relevance } & \multicolumn{3}{|c|}{ Changeability } & \multicolumn{3}{|c|}{ Moral Relevance } & \multicolumn{3}{|c|}{ Changeability } \\
\hline & $M$ & $S D$ & $\alpha$ & $M$ & $S D$ & $\alpha$ & $M$ & $S D$ & $\alpha$ & $M$ & $S D$ & $\alpha$ \\
\hline Purity & 1.73 & 0.79 & .49 & 4.13 & 1.33 & .65 & 1.63 & 0.89 & .57 & 4.40 & 1.27 & .41 \\
\hline Thinking and acting without vulgarity or filth & 1.79 & 0.96 & & 4.54 & 1.52 & & 1.67 & 1.07 & & 4.74 & 1.65 & \\
\hline Being wholesome and decent, relatively "pure" & 1.68 & 0.97 & & 3.72 & 1.55 & & 1.60 & 1.07 & & 4.05 & 1.54 & \\
\hline Trust & 1.68 & 0.64 & .28 & 4.03 & 1.10 & .42 & 1.62 & 0.73 & .37 & 4.41 & 1.24 & .59 \\
\hline Having a forgiving nature & 1.94 & 0.85 & & 3.97 & 1.44 & & 1.72 & 0.98 & & 4.25 & 1.51 & \\
\hline Tending to find fault with others & 1.41 & 0.83 & & 4.09 & 1.33 & & 1.52 & 0.89 & & 4.57 & 1.43 & \\
\hline Productiveness & 1.01 & 0.79 & .64 & 5.28 & 1.18 & .65 & 1.31 & 0.84 & .52 & 5.09 & 1.19 & .59 \\
\hline Being persistent, working until the task is finished & 1.18 & 1.05 & & 5.31 & 1.27 & & 1.60 & 1.08 & & 5.09 & 1.37 & \\
\hline Being lazy & 0.84 & 0.76 & & 5.25 & 1.47 & & 1.01 & 0.97 & & 5.09 & 1.46 & \\
\hline Anger & 0.98 & 0.66 & .66 & 4.04 & 1.12 & .63 & 1.20 & 0.8 & .66 & 4.22 & 1.33 & .71 \\
\hline Getting angry easily & 1.16 & 0.88 & & 4.09 & 1.33 & & 1.39 & 0.98 & & 4.24 & 1.52 & \\
\hline Being easily annoyed & 0.81 & 0.64 & & 4.00 & 1.28 & & 1.01 & 0.86 & & 4.20 & 1.52 & \\
\hline Intellectual Curiosity & 0.72 & 0.77 & .70 & 3.56 & 1.32 & .64 & 0.87 & 0.93 & .77 & 3.86 & 1.26 & .56 \\
\hline Being complex, a deep thinker & 0.79 & 0.90 & & 3.35 & 1.51 & & 0.91 & 1.04 & & 3.72 & 1.49 & \\
\hline Being curious about many different things & 0.66 & 0.86 & & 3.77 & 1.57 & & 0.83 & 1.02 & & 4.00 & 1.52 & \\
\hline Emotional Volatility & 0.64 & 0.66 & .54 & 3.75 & 1.25 & .61 & 0.93 & 0.82 & .60 & 3.98 & 1.22 & .60 \\
\hline Being emotionally stable, not easily upset & 0.75 & 0.89 & & 3.84 & 1.52 & & 1.09 & 1.07 & & 4.05 & 1.45 & \\
\hline Being moody, having up and down mood swings & 0.53 & 0.71 & & 3.65 & 1.43 & & 0.77 & 0.86 & & 3.90 & 1.44 & \\
\hline Organization & 0.50 & 0.76 & .84 & 5.45 & 1.13 & .66 & 1.04 & 1.02 & .81 & 5.23 & 1.31 & .72 \\
\hline Being organized & 0.50 & 0.86 & & 5.39 & 1.36 & & 1.11 & 1.17 & & 5.19 & 1.47 & \\
\hline Keeping things neat and tidy & 0.49 & 0.77 & & 5.50 & 1.26 & & 0.96 & 1.06 & & 5.27 & 1.50 & \\
\hline Depression & 0.60 & 0.71 & .55 & 4.27 & 1.21 & .47 & 0.90 & 0.88 & .59 & 4.47 & 1.10 & .32 \\
\hline Feeling secure, comfortable with self & 0.95 & 1.05 & & 4.65 & 1.38 & & 1.25 & 1.19 & & 4.95 & 1.41 & \\
\hline Feeling depressed, blue & 0.25 & 0.60 & & 3.89 & 1.61 & & 0.56 & 0.87 & & $\begin{array}{r}3.98 \\
\quad(t a\end{array}$ & 1.43 & 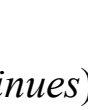 \\
\hline
\end{tabular}


Table S1 (continued)

\begin{tabular}{|c|c|c|c|c|c|c|c|c|c|c|c|c|}
\hline & \multicolumn{6}{|c|}{ Sample 1} & \multicolumn{6}{|c|}{ Sample 2} \\
\hline & \multicolumn{3}{|c|}{ Moral Relevance } & \multicolumn{3}{|c|}{ Changeability } & \multicolumn{3}{|c|}{ Moral Relevance } & \multicolumn{3}{|c|}{ Changeability } \\
\hline & $M$ & $S D$ & $\alpha$ & $M$ & $S D$ & $\alpha$ & $M$ & $S D$ & $\alpha$ & $M$ & $S D$ & $\alpha$ \\
\hline Energy Level & 0.55 & 0.67 & .59 & 4.19 & 1.16 & .62 & 0.95 & 0.89 & .70 & 4.30 & 1.18 & .56 \\
\hline Showing a lot of enthusiasm & 0.69 & 0.85 & & 4.51 & 1.35 & & 1.10 & 1.03 & & 4.54 & 1.41 & \\
\hline Being full of energy & 0.41 & 0.74 & & 3.88 & 1.38 & & 0.79 & 0.98 & & 4.05 & 1.43 & \\
\hline Creative Imagination & 0.54 & 0.78 & .77 & 3.26 & 1.17 & .66 & 0.92 & 0.96 & .72 & 3.79 & 1.23 & .70 \\
\hline Being original, coming up with new ideas & 0.56 & 0.89 & & 3.18 & 1.42 & & 0.94 & 1.11 & & 3.70 & 1.42 & \\
\hline Being inventive, finding clever ways to do things & 0.51 & 0.83 & & 3.33 & 1.27 & & 0.91 & 1.07 & & 3.87 & 1.39 & \\
\hline Anxiety & 0.45 & 0.64 & .72 & 3.95 & 1.25 & .69 & 0.89 & 0.82 & .55 & 4.24 & 1.19 & .62 \\
\hline Being relaxed, handling stress well & 0.65 & 0.88 & & 4.14 & 1.46 & & 1.10 & 1.13 & & 4.42 & 1.39 & \\
\hline Being someone who worries a lot & 0.25 & 0.51 & & 3.76 & 1.39 & & 0.67 & 0.83 & & 4.07 & 1.41 & \\
\hline Aesthetic Sensitivity & 0.37 & 0.68 & .81 & 3.54 & 1.57 & .81 & 0.66 & 0.87 & .80 & 3.70 & 1.45 & .77 \\
\hline Being fascinated by art, music, or literature & 0.44 & 0.81 & & 3.61 & 1.69 & & 0.69 & 0.96 & & 3.73 & 1.58 & \\
\hline Having artistic interests & 0.31 & 0.67 & & 3.46 & 1.74 & & 0.63 & 0.94 & & 3.67 & 1.63 & \\
\hline Assertiveness & 0.33 & 0.50 & .54 & 3.75 & 1.21 & .74 & 0.68 & 0.71 & .64 & 4.03 & 1.28 & .74 \\
\hline Being dominant, acting as a leader & 0.41 & 0.68 & & 3.99 & 1.30 & & 0.76 & 0.88 & & 4.14 & 1.39 & \\
\hline Having an assertive personality & 0.25 & 0.51 & & 3.52 & 1.42 & & 0.60 & 0.77 & & 3.93 & 1.48 & \\
\hline Sociability & 0.26 & 0.50 & .49 & 3.79 & 1.25 & .73 & 0.55 & 0.67 & .49 & 4.01 & 1.12 & .51 \\
\hline Being outgoing, sociable & 0.42 & 0.80 & & 3.95 & 1.25 & & 0.84 & 1.02 & & 4.25 & 1.37 & \\
\hline Being shy, introverted & 0.11 & 0.36 & & 3.63 & 1.55 & & 0.26 & 0.57 & & 3.78 & 1.38 & \\
\hline
\end{tabular}




\section{Do the Effects of Moral Relevance Hold Controlling for Perceived Changeability and Current Levels?}

\section{Perceived Changeability}

Although we were primarily interested in whether change goals depended on the moral relevance of a trait, moral relevance is just one dimension that the 21 traits might differ on. Another dimension that might matter is perceived changeability. Trait raters (described in the main text) rated "the degree to which an adult can change how much of the trait they possess, if they make a deliberate effort" on a 7-point scale $(1=$ Adults cannot change this trait at all, $4=$ Adults can moderately change this trait, $7=$ Adults can completely change this trait). We averaged the two items for each trait, before computing the average changeability rating for each trait across all raters.

We did not find a significant association between the extent to which traits were seen as more easily changeable and the extent to which targets wanted to change them, $r(19)=-.27,95 \%$ CI $[-.63, .18], p=.234$ (Sample 1) and $r(19)=-.23,95 \%$ CI $[-.60, .22], p=.307$ (Sample 2). Nor were targets significantly more or less likely to prioritize goals to improve traits that were rated as being more changeable, $r(19)=-.25,95 \%$ CI $[-.62, .20], p=.272$ (Sample 1) and $r(19)$ $=-.26,95 \% \mathrm{CI}[-.62, .19], p=.249$ (Sample 2). Finally, mirroring the results observed for targets, we did not find a significant association between the perceived changeability of a trait and the extent to which informants wanted to change them, $r(19)=-.32,95 \% \mathrm{CI}[-.66, .13], p=$ .163 (Sample 1) and $r(19)=-.34,95 \%$ CI $[-.67, .11], p=.136$ (Sample 2), or the extent to which informants prioritized goals to improve these traits, $r(19)=-.22,95 \% \mathrm{CI}[-.59, .24], p=.349$ (Sample 1) and $r(19)=-.21,95 \%$ CI $[-.59, .24], p=.362$ (Sample 2). However, an important caveat is that with 21 traits, we only had $80 \%$ power to detect correlations $\geq|.57|$. 
To gain greater precision in testing this question, we conducted exploratory (i.e., nonpreregistered) analyses using a multi-level modeling approach (implemented via lme4 and lmerTest; Bates, Mächler, Bolker, \& Walker, 2015; Kuznetsova, Brockhoff, \& Christensen, 2017). In each of these models, we predicted either continuous absolute change goals or priorities from perceived changeability and moral relevance (as simultaneous predictors), with 21 observations (for each of the 21 traits) nested within each participant. We conducted analyses separately for self- and informant-reported change goals. All models included random slopes for both perceived changeability and moral relevance, which allows each participant to have a different association between change goals and both perceived changeability and moral relevance. The models for the continuous change goals also had random intercepts, which allows each participant to have a different level of overall desired change (recall that this analysis was conducted on absolute scores that captured desired changes in either direction). The multi-level logistic regression models for predicting priorities only had a fixed intercept, because all participants had to select three priorities (which means that there was only within-persons variability, and no between-persons variability, on these outcome variables).

Across all models, the results showed that, controlling for perceived changeability, moral relevance continued to predict lowered change goals across both samples, for both self- and informant-perspectives, and for predicting continuous change goals and priorities (see Table S2). These results also provided some evidence that people were more inclined to change traits that independent raters had judged as being more changeable, though these effects were smaller and less consistent than the effects of moral relevance. 
Table S2

Within-Person Analyses Predicting Change Goals from Moral Relevance, Trait Levels, and Perceived Changeability

\begin{tabular}{|c|c|c|c|c|}
\hline & \multicolumn{2}{|c|}{ Sample 1} & \multicolumn{2}{|c|}{ Sample 2} \\
\hline & Changeability & Moral Relevance & Changeability & Moral Relevance \\
\hline \multicolumn{5}{|l|}{ Continuous $(\beta)$} \\
\hline \multirow[t]{2}{*}{ Self } & $0.06^{* * *}$ & $-0.33^{* * *}$ & $0.18^{* * *}$ & $-0.39^{* * *}$ \\
\hline & {$[0.03,0.09]$} & {$[-0.37,-0.29]$} & {$[0.15,0.2]$} & {$[-0.42,-0.35]$} \\
\hline \multirow[t]{2}{*}{ Informant } & $0.03^{*}$ & $-0.34^{* * *}$ & $0.16^{* * *}$ & $-0.44^{* * *}$ \\
\hline & {$[+0.00,0.07]$} & {$[-0.39,-0.30]$} & {$[0.12,0.2]$} & {$[-0.49,-0.39]$} \\
\hline \multicolumn{5}{|l|}{ Priorities (OR) } \\
\hline \multirow[t]{2}{*}{ Self } & 1.08 & $0.43^{* * *}$ & $1.31^{* * *}$ & $0.40^{* * *}$ \\
\hline & {$[0.99,1.17]$} & {$[0.39,0.48]$} & {$[1.22,1.42]$} & {$[0.37,0.44]$} \\
\hline \multirow[t]{3}{*}{ Informant } & 1.03 & $0.36^{* * *}$ & $1.55^{* * *}$ & $0.23^{* * *}$ \\
\hline & {$[0.92,1.15]$} & {$[0.29,0.44]$} & {$[1.39,1.72]$} & {$[0.18,0.29]$} \\
\hline & Trait Levels & Moral Relevance & Trait Levels & Moral Relevance \\
\hline \multicolumn{5}{|l|}{ Continuous $(\beta)$} \\
\hline \multirow[t]{2}{*}{ Self } & $-0.34^{* * *}$ & $-0.19^{* * *}$ & $-0.29^{* * *}$ & $-0.15^{* * *}$ \\
\hline & {$[-0.37,-0.31]$} & {$[-0.23,-0.16]$} & {$[-0.32,-0.26]$} & {$[-0.18,-0.13]$} \\
\hline \multirow[t]{2}{*}{ Informant } & $-0.55^{* * *}$ & $-0.10^{* * *}$ & $-0.51^{* * *}$ & $-0.10^{* * *}$ \\
\hline & {$[-0.59,-0.51]$} & {$[-0.13,-0.08]$} & {$[-0.55,-0.47]$} & {$[-0.13,-0.07]$} \\
\hline \multicolumn{5}{|l|}{ Priorities (OR) } \\
\hline \multirow[t]{2}{*}{ Self } & $0.37^{* * *}$ & $0.52^{* * *}$ & $0.40^{* * *}$ & $0.65^{* * *}$ \\
\hline & {$[0.33,0.41]$} & {$[0.46,0.59]$} & {$[0.37,0.43]$} & {$[0.59,0.71]$} \\
\hline \multirow[t]{2}{*}{ Informant } & $0.31^{* * *}$ & $0.75^{* *}$ & $0.34^{* * *}$ & $0.68^{* * *}$ \\
\hline & {$[0.28,0.35]$} & {$[0.63,0.89]$} & {$[0.30,0.38]$} & {$[0.59,0.79]$} \\
\hline
\end{tabular}

Note. Changeability and moral relevance were entered as simultaneous predictors in the first set of models. Trait levels and moral relevance were entered as simultaneous predictors in the second set of models. $\beta=$ standardized within-person effect, $\mathrm{OR}=$ odds ratio computed from standardized multilevel logistic regression coefficients. ${ }^{*} p<.05,{ }^{* *} p<.01,{ }^{* * *} p<.001 .95 \%$ confidence intervals are shown in brackets.

\section{Trait Levels}

Because ratings of most of the morally relevant traits tended to be quite high (on a 5-point scale anchored by strongly disagree and strongly agree), one remaining question is how much perceptions of current trait levels might play a role in explaining why people are less inclined to change moral traits. One possibility is that people believe that there is less room for improvement on moral traits. Because "agreeing strongly" with a given item (e.g., "Is compassionate, has a soft heart") is not the same as believing that you have the maximum possible levels of that trait, we 
do not have the data to test this idea. Such a test would require more direct measures of people's perceptions of room for improvement (e.g., measuring current levels using a response scale that ranges from $0=$ lowest possible levels to $10=$ highest possible levels).

A second possibility is that people are simply less motivated to improve moral traits because they already see themselves as being relatively high on such traits (compared to less morally relevant traits). This seems to be an inherently within-persons question, in contrast to the between-persons correlations we reported in the main text. Between-persons correlations between current levels and change goals for each trait ask whether people who are higher on a trait (relative to other people) want to change more on that trait (relative to other people). The withinpersons approach answers a complementary question- how trait levels and change goals are related at the within-person level (i.e., do people want to change less on traits that they see themselves as being relatively high on, compared to their other traits?). We also wanted to test whether people were still less inclined to change more morally relevant traits, controlling for their perceptions of their current levels (using this within-persons approach).

We explored these questions using the multi-level modeling approach described above (again, these analyses were not preregistered). The only difference was that we replaced perceived changeability with current levels as a predictor; thus, we predicted continuous absolute change goals or priorities from current levels and moral relevance (entered as simultaneous predictors). We reverse-scored current levels for the negative emotionality facets (anxiety, depression, emotionality, and anger), such that higher scores on all traits represent more desirable levels. Then, we centered current level scores around each person's mean, to ensure that all effects were at the within-person level.

Across both samples, the results showed that current levels and moral relevance independently predicted lowered change goals for both the continuous and priority-based 
measures, and for both self- and informant-perspectives (see Table S2). For example, in Sample 1, each $1 \mathrm{SD}$ increase in self-reported current levels and moral relevance (rated by independent raters) predicted an average $-0.34 \mathrm{SD}$ and -0.19 SD decrease in absolute change goals, respectively. In Sample 1, each $1 \mathrm{SD}$ increase in self-reported current levels and moral relevance also predicted an average decrease of 2.70 and 1.92, respectively, in the odds of prioritizing an improvement on a given trait (these lowered odds were calculating by taking the inverse of 0.37 and 0.52 , reported in Table S2). In other words, people were less inclined to change the traits that they saw themselves as having relatively more desirable levels of (compared with their other traits) — but even after controlling for targets' perceptions of their current levels, they were still less inclined to change more morally relevant traits (and the same was true from the perspective of informants). 


\section{Associations Between Informant-Reported Current Levels and Self-Reported Change}

\section{Goals}

Results for the associations between informant-reported current levels and self-reported change goals are shown in Table S10 in the OSF repository. The calibration to current traits was weaker (compared to the self-report-only correlations), but still generally held (Sample 1: mean $r$ $=-.20$; Sample 2: mean $r=-.21$ ). We also observed a substantial attenuation-by-morality effect in Sample $1(r(19)=.80,95 \%$ CI $[.56, .91], p<.001)$, though the 95\% CI just captured zero in Sample $2(r(19)=.43,95 \%$ CI $[-.00, .73], p=.052)$. To examine whether the size of the moral attenuation effect depended on whether current levels and change goals were both self-reported (vs. when only change goals were self-reported), we fit a linear mixed-effects model (with random intercepts for each trait) that regressed the Fisher $r$-to- $z$ transformed correlation between current levels and change goals for each trait onto the moral relevance of each trait, the method $(0$ $=$ self-reported current levels and change goals, $1=$ informant-reported current levels and selfreported change goals), and the interaction between moral relevance and method. A nonsignificant interaction in Sample 1 suggested that the size of the moral attenuation effect did not differ significantly when current levels and change goals were both self-reported, compared to when only change goals were self-reported, $b=-0.07,95 \%$ CI $[-0.21,0.07], p=.356$; however, this interaction was significant in Sample 2, suggesting that there was less of a moral attenuation effect when current levels were reported by informants, $b=-0.12,95 \%$ CI $[-0.23,-0.02], p=$ .035 . 


\section{Predicting Change Goal Priorities from Undesirable Current Levels}

To complement the correlational analyses, we predicted change goal priorities from undesirable current levels (modeled as latent variables) using logistic regression models implemented in Mplus Version 8.3 (Muthén \& Muthén, 1998-2017). We reversed the coefficients for all facets apart from negative emotionality; thus, the resulting odds ratios (ORs) reflect the extent to which each 1 SD difference towards the undesirable direction of a trait predicted a goal to prioritize improving that trait.

Figure S1 shows that in general, targets who self-reported less desirable levels of a trait were more likely to prioritize a goal to improve that trait (as one of their top three goals; Sample 1: mean $\mathrm{OR}=2.13 ;$ Sample 2: mean $\mathrm{OR}=2.10)$. These odds ratios trended towards being smaller for more morally relevant traits in Sample $1(r(19)=-.43,95 \%$ CI $[-.73,+.00], p=$ $.051)$, but not in Sample $2(r(19)=-.00,95 \%$ CI $[-.43, .43], p=.999)$.

Next, we predicted self-reported priorities from informant-reported current levels. These effects were smaller than for the self-report-only effects (Sample 1: mean OR $=1.38, t(20)=$ $4.38, p<.001$; Sample 2: mean $\mathrm{OR}=1.42, t(20)=4.00, p<.001)$. These effects were also smaller for more morally relevant traits in Sample $1(r(19)=-.49,95 \%$ CI $[-.76,-.08], p=.023)$, but not significantly so in Sample $2(r(19)=-.37,95 \%$ CI $[-.69, .08], p=.101)$, and this moral attenuation effect was similar compared to self-report-only effects (Sample 1: $b=0.06,95 \% \mathrm{CI}$ $[-0.17,0.30], p=.603$; Sample 2: $b=-0.15,95 \%$ CI $[-0.45,0.15], p=.341)$.

Finally, we predicted informant-reported priorities (from one randomly-selected informant) from aggregated informant-reported current levels. Because only two informants prioritized a goal to improve targets' loyalty in Sample 2, this point estimate was implausibly large $(\beta=20.34, \mathrm{OR}>680,000$; with very wide confidence intervals). Therefore, to avoid biasing the average odds ratios and other results reported here, we excluded this point estimate (for 
Sample 2 only). Overall, these odds ratios were descriptively stronger for nearly all traits, and were significantly larger compared to those obtained from self-reports only in Sample 1 (mean $\mathrm{OR}=2.76, t(20)=-2.17, p=.042)$, but not in Sample $2($ mean OR $=2.41, t(19)=-1.12, p=$ .276). Replicating the correlational results, informants' change goals remained calibrated to their perceptions of targets' current levels, even for more morally relevant traits (for correlations with moral relevance, Sample 1: $r(19)=.06,95 \%$ CI $[-.38, .48], p=.797$; Sample 2: $r(18)=-.03$, $95 \% \mathrm{CI}[-.46, .42], p=.908)$. The odds ratios for more morally relevant traits were larger when current levels and priorities were both informant-reported (vs. both self-reported) in Sample 1 ( $b$ $=0.28,95 \%$ CI $[0.03,0.54], p=.041)$, but not in Sample $2(b=-0.02,95 \%$ CI $[-0.47,0.43], p=$ $.944)$. 


\section{Sample 1}

Informant-Reported Traits and Change Priorities

Trait
Sociability
Assertiveness
Aesthetic Sensitivity
Anxiety
Organization
Creative Imagination
Energy Level
Depression
Emotional Volatility
Intellectual Curiosity
Anger
Productiveness
Trust
Purity
Responsibility
Compassion
Loyalty
Honesty
Respectfulness
Fairness
General Morality

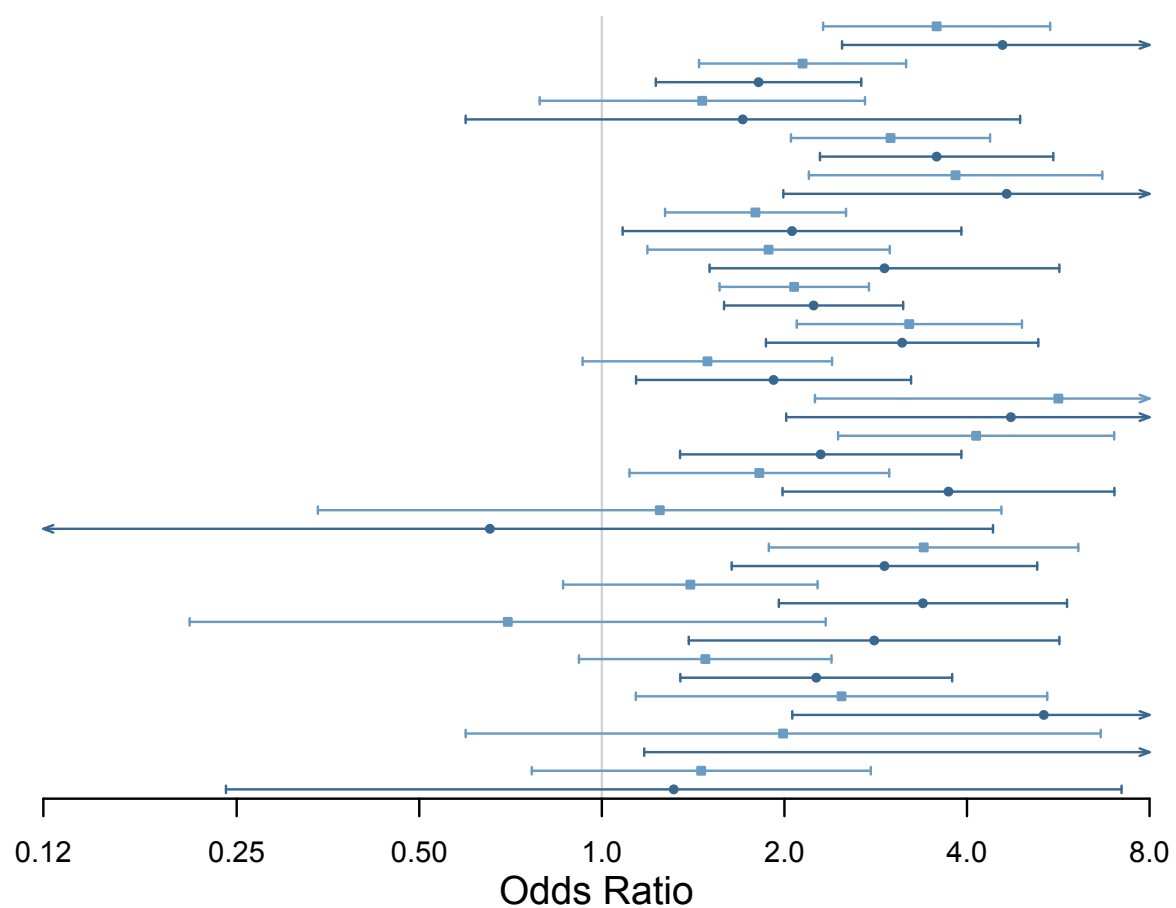

Sample 2

\section{Trait}

Sociability

Aesthetic Sensitivity

Assertiveness

Intellectual Curiosity

Anxiety

Depression

Creative Imagination

Emotional Volatility

Energy Level

Organization

Anger

Productiveness

Trust

Purity

Responsibility

Compassion

General Morality

Honesty

Loyalty

Fairness

Respectfulness

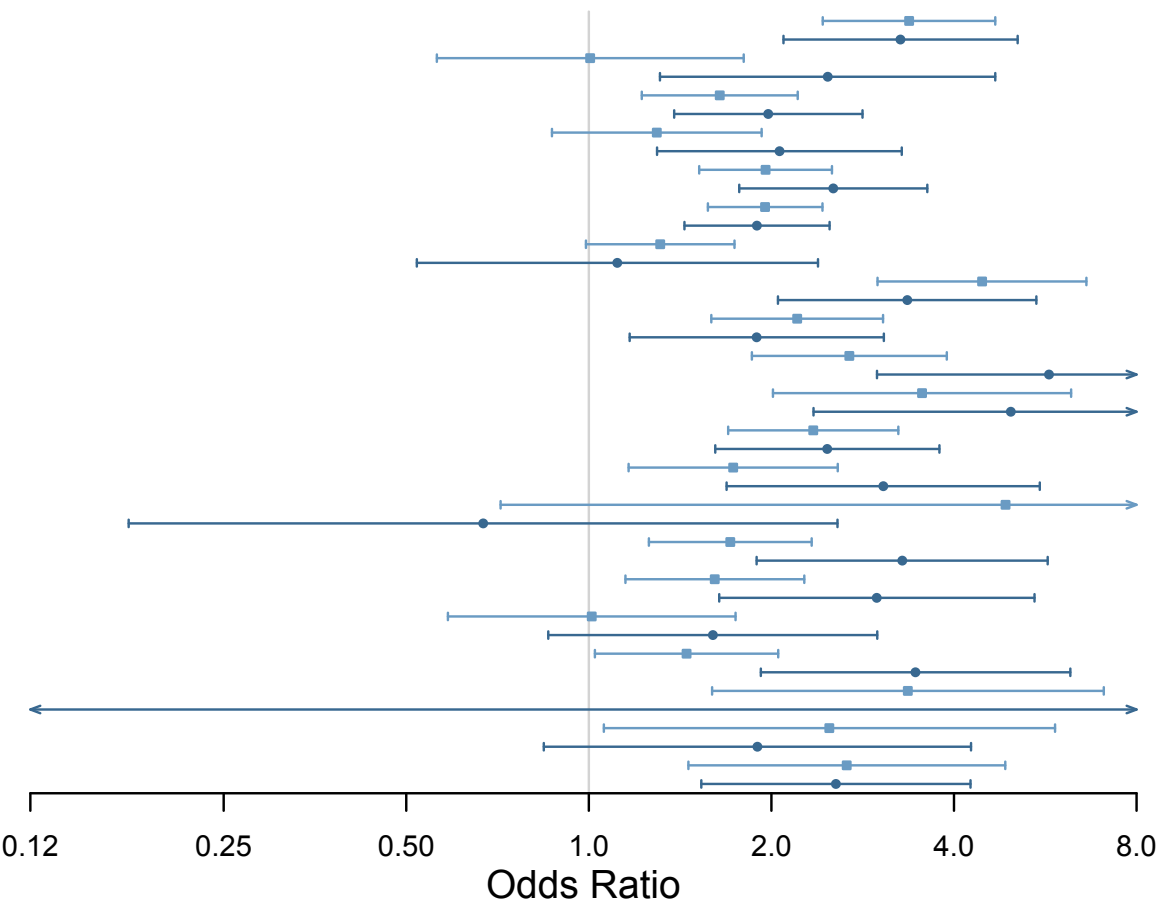

Figure S1. Odds ratios representing the change in odds of prioritizing a given improvement (as one of their top three goals) for every $1 \mathrm{SD}$ that a target was closer to the less desirable pole of that trait. Error bars depict the $95 \%$ confidence intervals. The traits are ordered from least to most morally relevant, based on the moral relevance norms for each respective sample. 


\section{Associations Between Moral Change Goals and Additional Individual Differences}

\section{Measures}

Descriptive statistics for these measures are reported in Table S3.

Honesty-Humility. Honesty-Humility is the sixth major dimension of personality in the HEXACO model (Ashton, Lee, \& de Vries, 2014), capturing preferences for fairness (e.g., "If I knew that I could never get caught, I would be willing to steal a million dollars" [r]), sincerity (e.g., "I wouldn't pretend to like someone just to get that person to do favors for me"), greed avoidance ("Having a lot of money is not especially important to me"), and modesty (e.g., "I think that I am entitled to more respect than the average person is" [r]). Targets and informants rated the target's Honesty-Humility using the 16-item subscale from the 100-item HEXACO Personality Inventory-Revised (Lee \& Ashton, 2018; 1 = Strongly disagree, $5=$ Strongly agree). We computed composites separately for self- and informant-rated Honesty-Humility.

Moral elevation. Moral elevation describes the tendency to be emotionally moved and to feel inspired to be a better person when witnessing displays of moral excellence (Thomson \& Siegel, 2017). Targets self-reported their trait moral elevation using the six "Engagement with Moral Beauty" items from the Engagement with Beauty Scale (Diessner, Solom, Frost, Parsons, \& Davidson, 2008). However, we replaced mentions of "moral beauty" with "moral excellence," as we thought this would improve the interpretability of the items (e.g., "When perceiving an act of moral excellence I feel emotional, it "moves me," such as feeling a sense of awe, or wonder or excitement or admiration or upliftment"; 1 = Very unlike me, 7 = Very much like me).

Impartial beneficence. The Oxford Utilitarianism Scale (Kahane et al., 2018) assesses individual differences in two dimensions of utilitarian thinking: instrumental harm (the willingness to harm innocent people for the greater good) and impartial beneficence (impartial concern for the greater good). Targets rated how much they endorsed five statements about the 
impartial promotion of people's welfare (e.g., "It is morally wrong to keep money that one doesn't really need if one can donate it to causes that provide effective help to those who will benefit a great deal"; 1 = Strongly disagree, 7 = Strongly agree).

Moral foundations. Targets completed the 20-item version of the Moral Foundations Questionnaire (Graham et al., 2011). This instrument assesses the extent to which people use and endorse the moral foundations of Harm/Care, Fairness/Reciprocity, Ingroup/Loyalty, Authority/Respect, and Purity/Sanctity (four items each). Ten items are worded in terms of the moral relevance of each foundation (e.g., "Whether or not someone violated standards of purity and decency"; $0=$ Not at all relevant, $5=$ Extremely relevant), and ten items ask participants to indicate their agreement or disagreement with statements (e.g., "Compassion for those who are suffering is the most crucial virtue"; $0=$ Strongly disagree, $5=$ Strongly agree).

Religiosity. Finally, targets completed a one-item measure of religiosity ("How religious are you?"; 1 = Not at all religious, 7 = Extremely religious).

\section{Results}

We were primarily interested in how strongly these individual differences correlated with highly morally relevant change goals (i.e., goals to change general morality, fairness, respectfulness, honesty, loyalty, compassion, responsibility, purity, and trust), but we examined all change goals to provide information on discriminant validity. We used semi-partial correlations to estimate the unique association between each individual difference and change goal, controlling for current levels on each respective trait. For example, to estimate the semipartial correlation between impartial beneficence and compassion change goals, we partialled out self-reported trait compassion. Here, we summarize the associations that replicated across both samples and that seemed theoretically noteworthy (but see Table S4 for all latent semi-partial correlations). 
The results for moral elevation and the moral foundations were somewhat ambiguous. Although targets who self-reported a greater tendency to experience moral elevation also tended to report greater desires to increase on almost all moral traits (across both samples), they also tended to report goals to improve several non-moral traits (e.g., intellectual curiosity, energy level, productiveness), controlling for current levels on these traits. Thus, moral elevation may be linked with a general desire for self-improvement. The Purity foundation was especially strongly associated with goals to become more pure, but the other foundations showed fewer, less specific, or inconsistent associations with moral change goals.

Religiosity, impartial beneficence, and Honesty-Humility were more specifically linked with moral change goals across both samples. More religious targets tended to report greater desires to increase on compassion and loyalty. Impartial beneficence, the tendency to value impartially maximizing the greater good, also showed theoretically sensible associations with goals to become fairer and more compassionate. Finally, targets who self-reported being higher on Honesty-Humility tended to report greater goals to increase on honesty. 
Table S3

Descriptive Statistics for Additional Measures

\begin{tabular}{|c|c|c|c|c|c|c|c|c|c|c|c|c|c|c|c|c|}
\hline \multirow[b]{3}{*}{ Trait } & \multicolumn{8}{|c|}{ Sample 1} & \multicolumn{8}{|c|}{ Sample 2} \\
\hline & \multicolumn{3}{|c|}{ Self-Report } & \multicolumn{4}{|c|}{ Informant-Report } & \multirow[b]{2}{*}{$r$} & \multicolumn{3}{|c|}{ Self-Report } & \multicolumn{4}{|c|}{ Informant-Report } & \multirow[b]{2}{*}{$r$} \\
\hline & $M$ & $S D$ & $\omega$ & $M$ & $S D$ & $\omega$ & $\operatorname{ICC}(1)$ & & $M$ & $S D$ & $\omega$ & $M$ & $S D$ & $\omega$ & $\operatorname{ICC}(1)$ & \\
\hline Honesty-Humility & 3.25 & 0.53 & .78 & 3.49 & 0.57 & .88 & .35 & $.49^{* * *}$ & 3.45 & 0.53 & .78 & 3.62 & 0.53 & .87 & .35 & $.42^{* * *}$ \\
\hline Moral Elevation & 5.16 & 0.91 & .77 & & & & & & 5.16 & 0.92 & .79 & & & & & \\
\hline Impartial Beneficence & 3.67 & 1.06 & .74 & & & & & & 3.96 & 1.03 & .73 & & & & & \\
\hline Religiosity & 3.25 & 1.75 & & & & & & & 2.99 & 1.88 & & & & & & \\
\hline Harm/Care Foundation & 3.42 & 0.73 & .59 & & & & & & 3.52 & 0.70 & .51 & & & & & \\
\hline Fairness Foundation & 3.65 & 0.63 & .61 & & & & & & 3.67 & 0.68 & .62 & & & & & \\
\hline Authority Foundation & 2.36 & 0.83 & .64 & & & & & & 2.58 & 0.81 & .54 & & & & & \\
\hline Ingroup Foundation & 2.48 & 0.85 & .62 & & & & & & 2.53 & 0.87 & .58 & & & & & \\
\hline Purity Foundation & 2.69 & 0.86 & .69 & & & & & & 2.89 & 0.81 & .60 & & & & & \\
\hline
\end{tabular}

Note. $\omega=$ omega reliability estimate, ICC $(1)=$ proportion of variability in informant ratings due to variability between targets (computed across informant ratings for targets who had two or more informants) , $r$ = latent self-other agreement correlations, estimated using structural equation models. ${ }^{* * *} p<.001$. 
Table S4

Semi-Partial Correlations Between Additional Moral Individual Differences and Self-Reported Moral Change Goals

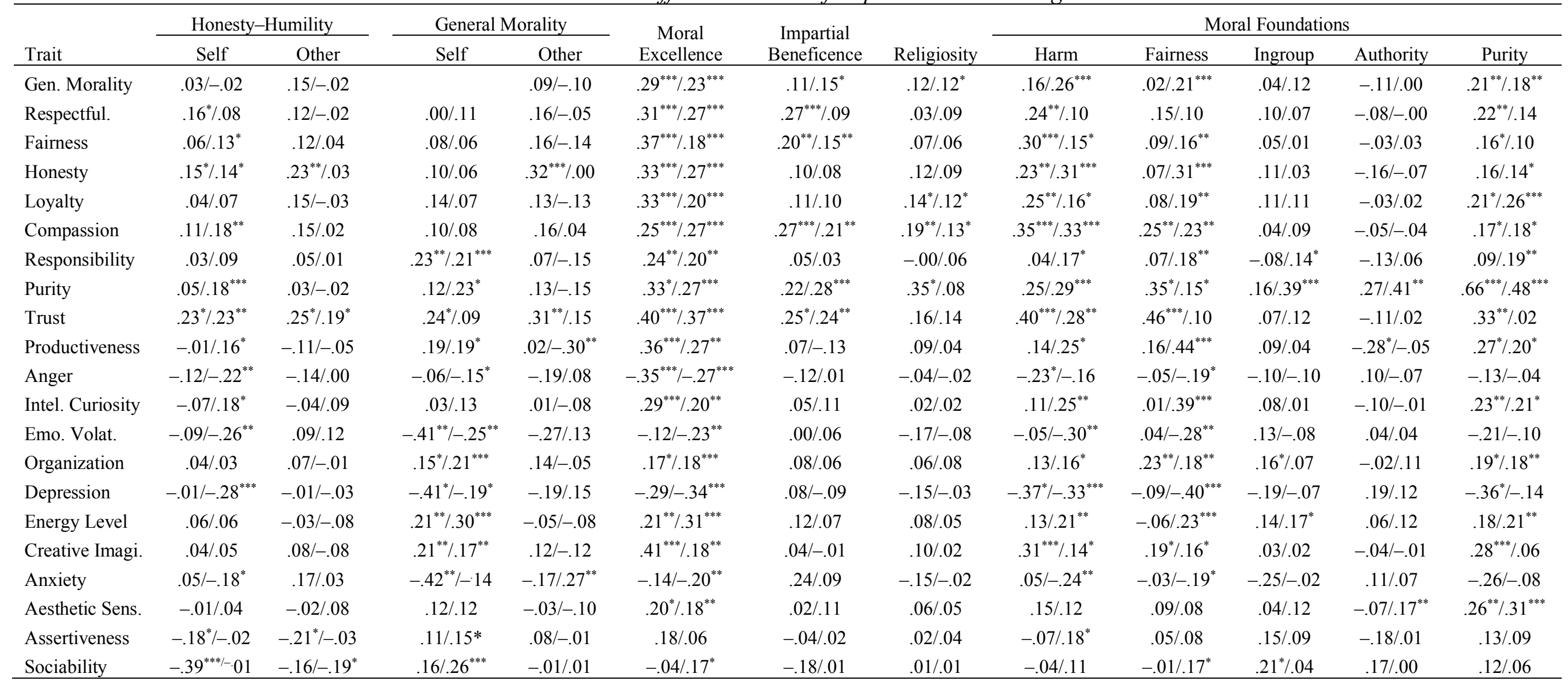

Note. Values left and right of each forward slash are for Sample 1 and Sample 2, respectively. Latent semi-partial correlations were computed using a structural equation modeling framework, to account for measurement unreliability. However, for Sample 2 only, we modeled the purity change goals as a single-indicator latent variable (where the observed purity change goal composite was the indicator, which assumed perfect reliability), as the preregistered models did not converge. Blank cell indicates that the analysis was not conducted (because it was not applicable). ${ }^{*} p<.05,{ }^{* *} p<.01,{ }^{* * *} p<.001$ (uncorrected for multiple comparisons). The change goals are ordered from least to most morally relevant, based on the average of the moral relevance norms across the two samples (weighted equally). 


\section{Reasons for Personality Change Goals}

We explored whether informants wanted to change targets' traits primarily for the targets' sake, or their own sake. To do so, we coded open-ended responses to one question about targets' and informants' top change goal for the target: "Why do you want [target's name] to change this aspect of your [their] personality?". After removing invalid responses (e.g., "N/A" or responses that stated that the participant didn't want the target to change), two research assistants coded whether targets' responses $\left(n_{\text {Sample1 }}=296 ; n_{\text {Sample2 }}=491\right)$ best reflected a concern for their own well-being or others' well-being, and whether informants' responses $\left(n_{\text {Sample } 1}=367 ; n_{\text {Sample2 }}=\right.$ 479) best reflected a concern for the target's well-being or the informant's own well-being. Coders selected "other" when the reason did not clearly reflect either category. The three categories were mutually-exclusive. Inter-rater agreement, as measured by the Cohen's kappa ( $\kappa$;

Cohen, 1960), was moderate to substantial for both the informant (Sample 1: .69; Sample 2: .50) and target (Sample 1:.62; Sample 2: .59) codings. The first author resolved discrepancies between the two coders. The coding instructions and the de-identified open-ended responses are available in the OSF repository.

As shown in Table S11, the majority of informants' reasons (Sample 1: 74.66\%; Sample 2: 78.91\%) reflected a concern for the targets' well-being (e.g., "She is way too nice to people and I feel others can easily take advantage of her"), and relatively few reasons (Sample 1: 18.53\%; Sample 2: 13.15\%) reflected the informant's self-interest (e.g., "[target's name] always sees the best in people - I, on the other hand, get annoyed with people easily and it's hard to complain about someone to [target's name]...”).

Similarly, the majority of targets' reasons (Sample 1: 84.46\%; Sample 2: 83.10\%) reflected a concern for their own well-being (e.g., "I worry a lot about silly things, and it 
prevents me from getting the most happiness out of my life"), and very few reasons (Sample 1: 12.16\%; Sample 2: 12.02\%) reflected a concern for others' well-being (e.g., “...I want to be there for my friends and family when they need someone").

Finally, we explored whether these patterns varied depending on the moral relevance of the change goals. Because some change goals were rarely prioritized (see Table S11), for these low-frequency change priorities, the percentage of reasons that reflected a benefit to the self or to others were unlikely to be reliable estimates (e.g., if only 4 people prioritized a goal to become more honest, the estimates of $75 \%$ and $25 \%$ for reasons that benefit the self vs. benefit others would be very unreliable). This makes it unwise to examine the effects of moral relevance in a continuous way. Instead, we grouped the change goals into moral improvements (goals to be more moral, fair, respectful, honest, loyal, compassionate, responsible, trusting, and pure) and non-moral improvements (all other improvements), because there was a notable gap in moral relevance ratings between the least morally relevant trait among the moral traits (Sample 1: $M_{\text {Purity }}=1.73 ;$ Sample $\left.2: M_{\text {Trust }}=1.62\right)$ and the most morally relevant trait among the non-moral traits (Sample 1: $M_{\text {Productiveness }}=1.01 ;$ Sample 2: $\left.M_{\text {Productiveness }}=1.31\right)$.

We excluded the "Other" category and goals to change in the undesirable direction. Then, we computed the odds ratios (using Fisher's exact test) for 2 (moral or non-moral improvement) $\times 2$ (benefit target or benefit informant/others) contingency tables, separately for target- and informant-reported reasons. For the target-reported reasons, the odds of stating that the change would benefit others (vs. the target) were 98.11 (Sample 1; 95\% CI [28.20, 448.50], $p<.001$ ) and 59.12 (Sample 2; 95\% CI [26.48, 141.25], $p<.001$ ) times higher for moral (vs. non-moral) improvements. Similarly, for the informant-reported reasons, the odds of stating that the change would benefit the informant (vs. the target) were 27.26 (Sample 1; 95\% CI [11.44, 71.37], $p<$ 
.001 ) and 19.28 (Sample 2; 95\% CI [9.11, 42.17], $p<.001$ ) times higher for moral (vs. nonmoral) improvements. Therefore, both targets and informants wanted the target to make nonmoral improvements for the target's own sake, but moral improvements for the sake of others. 


\section{Replication Study Establishing Generalizability to Older Adults}

Several readers and audiences have expressed curiosity about whether the key finding (that people don't particularly want to be more moral) generalizes beyond college students or young adults. To address this question, we conducted another preregistered replication with a sample of relatively older adults. Because we conducted this additional replication after the paper was accepted, this section has not been peer-reviewed. The data, code, materials, and preregistration can be accessed at https://osf.io/cbxjh.

\section{Method}

We aimed to recruit 220 participants from Amazon's Mechanical Turk, who were compensated with \$2 USD. We restricted participation to US-based participants who had a HIT approval rate $\geq 95 \%$. To oversample for older adults, we recruited participants in three batches: 1) 50 participants who were between the ages of $45-55,2) 50$ participants who were age 55 or older, and 3) 120 participants with no age restrictions. Following our preregistered exclusion criteria, we excluded 23 incomplete responses and four participants who failed a simple attention check ("Please select the Agree button"). After these exclusions, Sample 3 comprised 222 targets (104 female, 117 male, 1 other or not disclosed) between the ages of 22 and 78 years $\left(M_{\text {age }}=\right.$ 45.4, $\left.S D_{\text {age }}=13.82\right)$. Targets identified as White/Caucasian $(n=180)$, Black/African American $(n=18)$, Hispanic/Latino $(n=8)$, Asian $(n=4)$, or other/multiple $(n=12)$.

Targets self-reported their personality traits, change goals, and change goal priorities using the same measures described in the paper (along with additional exploratory measures, reported in the codebook). Targets also rated the moral relevance of the 42 items that were included in the change goals survey, using the same measures described in the paper. Thus, unlike the procedure in Samples 1 and 2, in which we obtained moral relevance ratings 
from participants who were not involved in the main study, in Sample 3, the moral relevance ratings were provided by the targets themselves. This provides person-specific moral relevance ratings, which we use in the within-person analyses reported below. In addition, unlike Samples 1 and 2, we did not recruit informants. All other data analytic procedures for the analyses we included in this replication study were identical to those reported in the main text.

\section{Results and Discussion}

Descriptive statistics for the key measures are shown in Table S5.

Table S5

Descriptive Statistics for Personality Traits, Change Goals, and Moral Relevance Norms

\begin{tabular}{|c|c|c|c|c|c|c|c|c|c|}
\hline \multirow[b]{2}{*}{ Trait } & \multicolumn{3}{|c|}{ Trait Levels } & \multicolumn{3}{|c|}{ Change Goals } & \multicolumn{3}{|c|}{ Moral Relevance } \\
\hline & $M$ & $S D$ & $\omega$ & $M$ & $S D$ & $\alpha$ & $M$ & $S D$ & $\alpha$ \\
\hline General Morality & 3.93 & 0.65 & .67 & 0.61 & 0.71 & .80 & 2.61 & 0.61 & .74 \\
\hline Honesty & 4.17 & 0.72 & .77 & 0.60 & 0.70 & .67 & 2.47 & 0.71 & .76 \\
\hline Fairness & 4.35 & 0.66 & .76 & 0.61 & 0.70 & .79 & 2.46 & 0.69 & .78 \\
\hline Compassion & 3.94 & 0.86 & .77 & 0.63 & 0.68 & .74 & 2.36 & 0.71 & .65 \\
\hline Respectfulness & 4.11 & 0.84 & .83 & 0.55 & 0.76 & .45 & 2.33 & 0.67 & .55 \\
\hline Loyalty & 4.07 & 0.81 & 29 & 0.51 & 0.68 & .74 & 2.10 & 0.88 & .78 \\
\hline Purity & 3.29 & 0.87 & .11 & 0.40 & 0.67 & .50 & 1.89 & 0.98 & .77 \\
\hline Trust & 3.44 & 0.93 & .73 & 0.63 & 0.71 & .23 & 1.87 & 0.76 & .58 \\
\hline Responsibility & 3.84 & 0.87 & .70 & 0.69 & 0.75 & .79 & 1.83 & 0.90 & .73 \\
\hline Anger & 2.40 & 1.04 & .48 & -0.66 & 1.09 & .88 & 1.36 & 0.83 & .66 \\
\hline Productiveness & 3.82 & 0.93 & .81 & 0.81 & 0.79 & .39 & 1.21 & 0.90 & .58 \\
\hline Emotional Volatility & 2.37 & 0.99 & .81 & -0.77 & 0.83 & .49 & 0.93 & 0.94 & .72 \\
\hline Organization & 3.79 & 0.98 & .83 & 0.86 & 0.71 & .72 & 0.74 & 0.97 & .80 \\
\hline Depression & 2.36 & 1.05 & .84 & -0.87 & 0.86 & .56 & 0.73 & 0.94 & .73 \\
\hline Anxiety & 2.83 & 1.09 & .83 & -0.96 & 0.85 & .49 & 0.68 & 0.90 & .73 \\
\hline Energy Level & 3.31 & 0.94 & .71 & 0.95 & 0.67 & .63 & 0.66 & 0.93 & .79 \\
\hline Aesthetic Sensitivity & 3.62 & 1.09 & .77 & 0.70 & 0.68 & .69 & 0.64 & 0.98 & .87 \\
\hline Creative Imagination & 3.86 & 0.96 & .83 & 0.90 & 0.65 & .67 & 0.63 & 0.95 & .85 \\
\hline Intellectual Curiosity & 3.87 & 0.93 & .78 & 0.66 & 0.67 & .46 & 0.62 & 0.92 & .86 \\
\hline Assertiveness & 3.04 & 0.93 & .69 & 0.54 & 0.76 & .71 & 0.57 & 0.82 & .75 \\
\hline Sociability & 2.91 & 1.09 & .84 & 0.76 & 0.76 & .33 & 0.54 & 0.82 & .70 \\
\hline
\end{tabular}

Note. $\omega=$ omega reliability estimates for three- to four-item scales or $\alpha$ reliability estimates for the two-item honesty, fairness, loyalty, and purity scales. Traits are ordered from most to least morally relevant. The means for the change goals (reported in this table) were computed from the raw change goals, but we used mean absolute change goals for the correlations with moral relevance (reported in the text). 
Do people want to be more moral? Overall, targets showed a lower desire to change on traits that were more morally relevant, $r(19)=-.67,95 \% \mathrm{CI}=[-.86,-.34], p<.001$ (see Figure S2, Panel A). On the priorities measure (see Figure S2, Panel B), targets prioritized goals to become more energetic (22.97\%) about as often as goals to become less anxious $(25.23 \%)$ and depressed (23.42\%). In other words, compared to younger adults in Samples 1 and 2, goals to reduce anxiety and depression were relatively less important for these older adults. However, these older adults were still less inclined to prioritize more morally relevant improvements, $r(19)$ $=-.68,95 \% \mathrm{CI}=[-.86,-.35], p<.001$ (see Figure S2, Panel B). In other words, the finding that people are less inclined to improve moral traits is not only limited to college students.
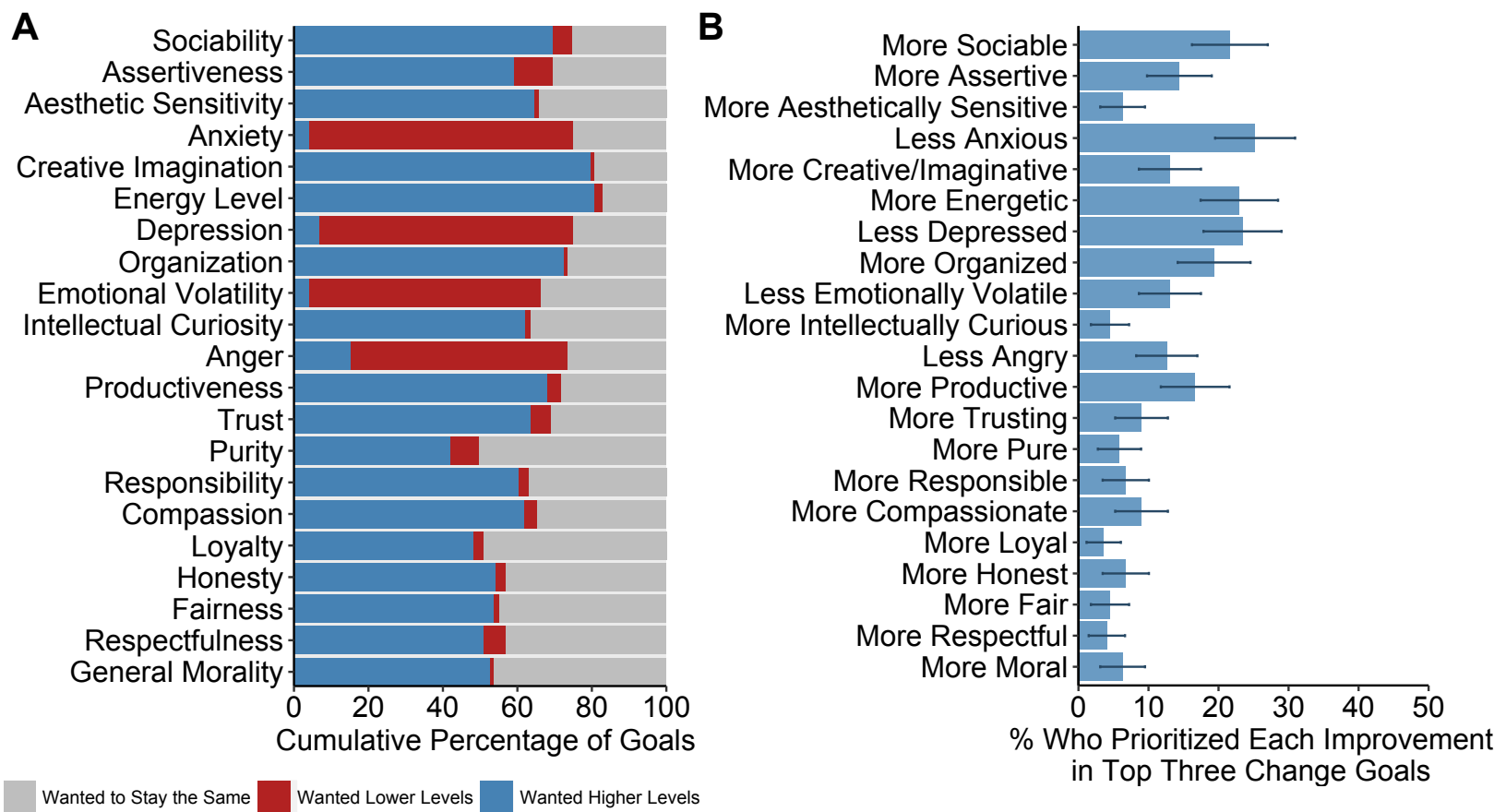

Figure S2. Panel A shows the categorical summary of ratings on the change goals scale for Sample 3. Stacked bars on the left show the percentage of targets who wanted higher levels, lower levels, or the same level of each trait. Panel B shows the percentage of targets who prioritized each trait as one of their top three most desired changes. Error bars depict 95\% confidence intervals. For both panels, to facilitate visual comparison with Samples 1 and 2, we have ordered the traits from least to most morally relevant on the basis of the average of the moral relevance norms across Samples 1 and 2 (weighted equally). However, in the analyses for Sample 3, we used the moral relevance norms from Sample 3. 
Associations between traits and change goals. Figure S3 shows the latent correlations between self-reported current levels and change goals for each trait. In general, targets who reported having lower levels of a given trait wanted to increase more on that trait, mean $r=-.27$. However, once again, the negative association between traits and change goals was smaller for more morally relevant traits, as shown by a strong positive association between moral relevance scores and (Fisher $r$-to- $z$ transformed) correlations between traits and change goals, $r(19)=.49$, $95 \%$ CI $[.07, .76], p=.025$. In other words, the correlation between current levels and the desire to improve shifted from moderately negative for the least morally relevant traits to essentially zero for the most morally relevant traits.

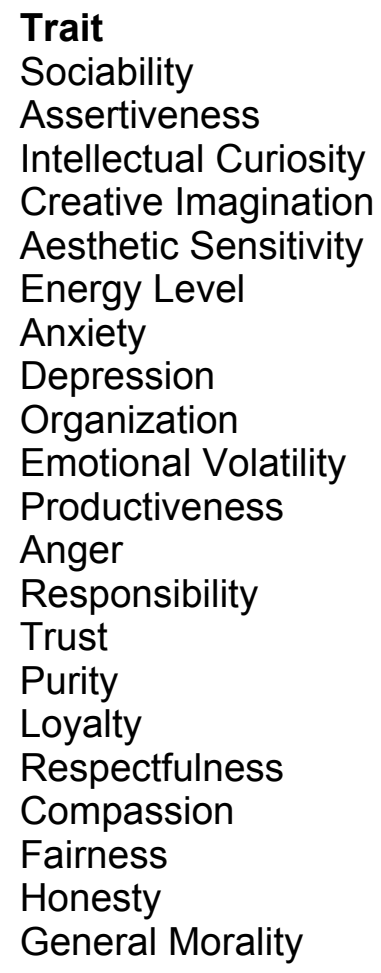

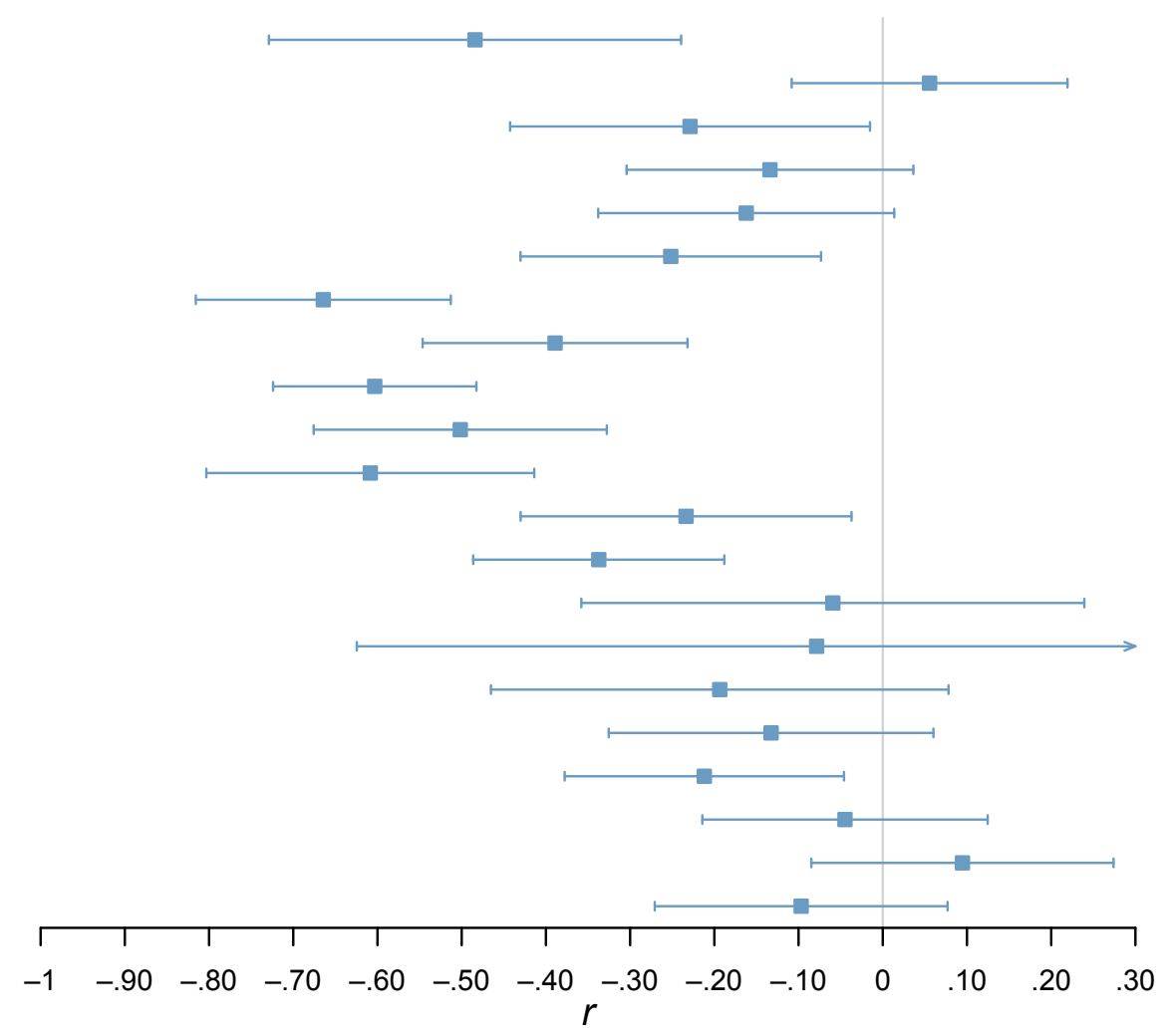

Figure S3. Associations between self-reported current traits and change goals. The traits are ordered from least to most morally relevant on the basis of the moral relevance norms for Sample 3. Error bars depict $95 \%$ confidence intervals. 
Do high trait levels explain why people do not want to be more moral? Finally, we used multi-level modeling to examine whether people are less motivated to change more morally relevant traits, controlling for their perceptions of their current levels. We used the same approach described above (see Section 3), except that we used person-specific measures of moral relevance (rather than aggregate moral relevance scores), which were within-person-centered. Once again, these within-person analyses showed that current levels and moral relevance scores independently predicted lowered change goals for both the continuous and priority-based measures. In other words, targets were less inclined to change on traits that they considered to be more morally relevant $(\beta=-0.13,95 \% \mathrm{CI}[-0.16,-0.09], p<.001)$, even controlling for current levels $(\beta=-0.15,95 \%$ CI $[-0.20,-0.09], p<.001)$. They were also less inclined to prioritize improving traits that they considered to be more morally relevant $(\mathrm{OR}=0.67,95 \% \mathrm{CI}[0.60$, 0.76], $p<.001)$, even controlling for current levels ( $\mathrm{OR}=0.56,95 \%$ CI $[0.51,0.63], p<.001)$. 


\section{References}

Ashton, M. C., Lee, K., \& de Vries, R. E. (2014). The HEXACO honesty-humility, agreeableness, and emotionality factors: A review of research and theory. Personality and Social Psychology Review, 18(2), 139-152. https://doi.org/10.1177/1088868314523838

Bates, D., Mächler, M., Bolker, B., \& Walker, S. (2015). Fitting linear mixed-effects models using lme4. Journal of Statistical Software, 67(1), 1-48. https://doi.org/10.18637/jss.v067.i01

Cohen, J. (1960). A coefficient of agreement for nominal scales. Educational and Psychological Measurement, 20(1), 37-46. https://doi.org/10.1177/001316446002000104

Diessner, R., Solom, R. C., Frost, N. K., Parsons, L., \& Davidson, J. (2008). Engagement with beauty: Appreciating natural, artistic, and moral beauty. Journal of Psychology: Interdisciplinary and Applied, 142(3), 303-329. https://doi.org/10.3200/JRLP.142.3.303332

Graham, J., Nosek, B. A., Haidt, J., Iyer, R., Koleva, S., \& Ditto, P. H. (2011). Mapping the moral domain. Journal of Personality and Social Psychology, 101(2), 366-385. https://doi.org/10.1037/a0021847

Kahane, G., Everett, J. A. C., Earp, B. D., Caviola, L., Faber, N. S., Crockett, M. J., \& Savulescu, J. (2018). Beyond sacrificial harm: A two-dimensional model of utilitarian psychology. Psychological Review, 125(2), 131-164. https://doi.org/10.1037/rev0000093

Kuznetsova, A., Brockhoff, P. B., \& Christensen, R. H. B. (2017). lmerTest package: Tests in linear mixed effects models. Journal of Statistical Software, 82(13), 1-26. https://doi.org/10.18637/jss.v082.i13

Lee, K., \& Ashton, M. C. (2018). Psychometric properties of the HEXACO-100. Assessment, 
25(5), 543-556. https://doi.org/10.1177/1073191116659134

Muthén, L., \& Muthén, B. O. (1998-2017). Mplus user's guide (8th ed.). Los Angeles: Muthén \& Muthén.

Thomson, A. L., \& Siegel, J. T. (2017). Elevation: A review of scholarship on a moral and otherpraising emotion. Journal of Positive Psychology, 12(6), 628-638.

https://doi.org/10.1080/17439760.2016.1269184 